\title{
PHF20 is an effector protein of p53 double lysine methylation that stabilizes and activates p53
}

\author{
Gaofeng Cui ${ }^{1,6}$, Sungman Park 2,6 , Aimee I Badeaux ${ }^{3,6}$, Donghwa Kim ${ }^{2,6}$, Joseph Lee ${ }^{1}$, \\ James R Thompson ${ }^{4}$, Fei Yan², Satoshi Kaneko ${ }^{2,5}$, Zengqiang Yuan ${ }^{2,5}$, Maria Victoria \\ Botuyan ${ }^{1}$, Mark T Bedford ${ }^{3}$, Jin Q Cheng ${ }^{2}$, and Georges Mer ${ }^{1}$ \\ ${ }^{1}$ Department of Biochemistry and Molecular Biology, Mayo Clinic, Rochester, Minnesota, USA \\ 2Department of Molecular Oncology, H. Lee Moffitt Cancer Center and Research Institute, \\ Tampa, Florida, USA \\ ${ }^{3}$ Department of Molecular Carcinogenesis, The University of Texas M.D. Anderson Cancer \\ Center, Smithville, Texas, USA
}

${ }^{4}$ Department of Physiology and Biomedical Engineering, Mayo Clinic, Rochester, Minnesota, USA

\begin{abstract}
PHF20 is a multidomain protein and subunit of a lysine acetyltransferase complex that acetylates histone $\mathrm{H} 4$ and $\mathrm{p} 53$ but whose function is unclear. Using biochemical, biophysical and cellular approaches, we determined that PHF20 is a direct regulator of p53. A Tudor domain in PHF20 recognized p53 dimethylated at Lys370 or Lys382 and a homodimeric form of this Tudor domain could associate with the two dimethylated sites on p53 with enhanced affinity, indicating a multivalent interaction. Association with PHF20 promotes stabilization and activation of p53 by diminishing Mdm2-mediated p53 ubiquitylation and degradation. PHF20 contributes to upregulation of p53 in response to DNA damage, and ectopic expression of PHF20 in different cell lines leads to phenotypic changes that are hallmarks of p53 activation. Overall our work establishes that PHF20 functions as an effector of p53 methylation that stabilizes and activates p53.
\end{abstract}

(C) 2012 Nature America, Inc. All rights reserved.

Correspondence should be addressed to G.M. (mer.georges@mayo.edu), J.Q.C. (jin.cheng@moffitt.org) or M.T.B. (mtbedford@mdanderson.org).

${ }_{5}^{6}$ These authors contributed equally to this work.

5 Present addresses: Children's Hospital, Harvard Medical School, Boston, Massachusetts, USA (S.K.) and Institute of Biophysics, Chinese Academy of Sciences, Beijing, China (Z.Y.).

Note: Supplementary information is available in the online version of the paper.

\section{AUTHOR CONTRIBUTIONS}

G.C. designed and prepared the fusion proteins and all peptides with incorporation of methyllysine analogs, determined the crystal structure of PHF20 Tudor1 and did the NMR spectroscopy-based experiments including structure determination and binding assays. S.P. and D.K. designed and performed the in vivo mutagenesis studies, the ubiquitylation assays, the DNA damage assays and the cell cycle regulation assays. A.I.B. designed and performed the protein array assays and cell biology experiments. J.L. determined the crystal structure of PHF20 Tudor2. J.R.T. contributed to the refinement of crystal structures. F.Y., S.K. and Z.Y. contributed to the cell biology experiments. M.V.B. designed and performed the p53 methylation assay with SET8 and SMYD2 and contributed extensively to the preparation of proteins used for structural studies. M.T.B., J.Q.C. and G.M. supervised the research in their respective laboratories. G.M. wrote the manuscript with input from the other authors.

COMPETING FINANCIAL INTERESTS

The authors declare no competing financial interests.

Reprints and permissions information is available online at http://www.nature.com/reprints/index.html. 
The tumor suppressor protein p53, mutated in half of all human cancers, is a transcription factor regulated by several post-translational modifications, including phosphorylation, ubiquitylation, acetylation and methylation ${ }^{1,2}$. Depending on the site and extent of lysine methylation, p53 transcriptional activity is activated or inhibited. Monomethylation of Lys372 or dimethylation of Lys370 promotes p53-activated transcription, whereas monomethylation of Lys370 or Lys382 suppresses p53-mediated transcription ${ }^{3-6}$. Dimethylation of Lys382 has been implicated in the recruitment of p53 to sites of DNA damage 6,7 .

How lysine methylation affects p53 function is poorly understood ${ }^{8}$. The best characterized effector for p53 methylation is 53BP1, a protein involved in cell-cycle checkpoint signaling and DNA repair. In 53BP1, tandem BRCA1 C terminus (BRCT) domains associate with the DNA-binding core domain of p53 (refs. 9,10) and its tandem Tudor domains recognize p53 dimethylated at Lys370 (p53K370me2) or Lys382 (p53K382me2) 4,6,7,11. Previously, we showed that 53BP1 tandem Tudor domains bind histone H4 dimethylated at Lys20 (H4K20me2) 12,13 and identified a Tudor domain in human PHF20 (plant homeodomain finger-containing protein 20, also known as glioma-expressed antigen 2, GLEA2) as another H4K20me 2 binder $^{12}$.

PHF20 was initially described as an immunogenic antigen that elicits a strong antibody response in glioblastoma and adenocarcinoma patients ${ }^{14-16}$. Later, it was shown that PHF20 can transcriptionally activate p53 and be downregulated through phosphorylation by the Akt kinase $^{17}$. PHF20 was also identified as a component of the 'male absent on the first' (MOF) lysine acetyltransferase ${ }^{18-22}$, which together with $O$-linked $\beta$ - $N$-acetylglucosamine transferase, isoform 1 (OGT1) form the nonspecific lethal (NSL) complex ${ }^{20,22}$. In the context of the NSL complex, MOF lysine acetyltransferase acetylates Lys120 in the DNAbinding domain of p53 when DNA damage occurs ${ }^{21}$, promoting p53-dependent transcription of pro-apoptotic genes without altering transcription of cell-cycle genes ${ }^{23}$. OGT1, in contrast, modifies p53 at Ser149, inducing p53 stabilization by preventing ubiquitindependent proteolysis ${ }^{24}$. The NSL complex, through MOF lysine acetyltransferase, acetylates histone H4 at Lys5, Lys8 and Lys16 (ref. 22). Recent studies showed that Phf20null mice die shortly after birth and that loss of PHF20 results in reduced expression of genes whose promoters are marked with high levels of H4K16ac, thus directly implicating PHF20 in transcriptional regulation ${ }^{25}$.

Here we set out to probe the function of human PHF20. We demonstrate that PHF20 specifically binds K370me2- or K382me2- containing p53 peptides in vitro. We characterize these interactions in detail using protein domain arrays, X-ray crystallography, NMR spectroscopy, calorimetry and cell assays, and show that one of the two Tudor domains in PHF20 contributes to the interaction with p53. A homodimeric form of this Tudor domain can bind doubly dimethylated p53 (p53K370me2K382me2), greatly strengthening the PHF20-p53 interaction in vitro. Functionally, we show that the PHF20-p53 association diminishes p53 ubiquitylation. Therefore, PHF20 emerges as a regulator of p53. PHF20 has the unique property of being a p53-specific transcription factor that also stabilizes p53 through direct interaction in a methylation-dependent manner.

\section{RESULTS}

\section{Interaction of PHF20 with p53 in vitro and in cells}

To probe the function of human PHF20, we conducted experiments in vitro and in cells (Fig. 1). Based on its amino acid sequence, PHF20 is predicted to contain several domains including two Tudor domains, a plant homeodomain (PHD) finger and putative DNAbinding domains AT hook and $\mathrm{C}_{2} \mathrm{H}_{2}$-type zinc finger (Fig. 1a). In an initial systematic 
screen using an array of more than 120 protein domains probed with methylated peptides, we identified PHF20 as a binder of methylated p53 (data not shown). Of the four known methylated forms of p53, p53K370me2 and p53K382me2 exhibited the strongest interaction with PHF20 (Supplementary Fig. 1). We used a condensed protein domain array including the two Tudor domains of PHF20 and homolog PHF20-like 1 (PHF20L1), with 53BP1 tandem Tudor domains serving as a positive control, to gauge binding of these domains to p53 peptides methylated to different degrees at Lys370 or Lys382 (Fig. 1b). The results indicated that the second Tudor domain of PHF20 (PHF20 Tudor2) alone or in combination with the first Tudor domain (PHF20 Tudor1-2) interacted most strongly with p53K370me2 and p53K382me2 peptides, whereas the first Tudor domain alone (PHF20 Tudor1) exhibited no interaction (Fig. 1b). These data suggest that the Tudor domains of PHF20 are independent modules. In agreement with these data, the ${ }^{1} \mathrm{H}^{-15} \mathrm{~N}$ heteronuclear single quantum coherence (HSQC) NMR spectra of the individual Tudor domains (PHF20 Tudor1 and PHF20 Tudor2) did not change when the other Tudor domain was also present (PHF20 Tudor1-2) (Fig. 2a). We thus conclude that PHF20 Tudor2 can function alone in contrast to 53BP1 or JMJD2A, which both use double Tudor domains to bind methylated targets ${ }^{13,26,27}$.

To evaluate the biological relevance of the PHF20-p53 interaction, we tested whether the two proteins could form a complex in vivo using co-immunoprecipitation (co-IP) assays. Before this, we probed the cellular localization of EGFP-tagged full-length PHF20 and PHF20 Tudor1-2 constructs and found that both proteins were nuclear (Fig. 1c). We observed, however, that EGFP-PHF20 Tudor1-2 was also present in the nucleoli, something not seen with the full-length protein (Fig. 1c). We co-immunoprecipitated EGFP-p53 and Flag-PHF20 from lysates of human embryonic kidney (HEK 293) cells expressing these proteins using an anti-Flag antibody or an anti-p53 antibody (Fig. 1d), revealing an interaction between PHF20 and p53. Similarly, endogenous p53 immunoprecipitated with EGFP-PHF20 Tudor1-2 using an anti-GFP antibody (Fig. 1d). We also found that endogenous full-length PHF20 interacted with endogenous p53 in cell lines U87 (glioblastoma) and MCF7 (breast cancer), which both express wild-type p53 (Fig. 1e).

\section{PHF20 homodimerizes via its second Tudor domain}

Although the first Tudor domain of PHF20 is monomeric, the second Tudor domain forms a stable homodimer cross-linked by two disulfide bonds. Dimerization was evident from the increased retention time in size exclusion chromatography and sharpening of all signals in the ${ }^{1} \mathrm{H}_{-}{ }^{15} \mathrm{~N}$ HSQC spectrum of PHF20 Tudor2 after we added DTT or when we mutated Cys96 and Cys100 to serines (Supplementary Fig. 2a). We confirmed the dimeric state by mass spectrometry analysis. Conversion of dimeric PHF20 Tudor2 to a monomeric species (mPHF20 Tudor2) by mutating Cys96 and Cys100 did not affect the structure of the domain. In the presence of $20 \mathrm{mM}$ DTT, the majority of signals in the ${ }^{1} \mathrm{H}-{ }^{15} \mathrm{~N}$ HSQC spectra of mPHF20 Tudor2 and wild-type PHF20 Tudor2 were superimposable (Supplementary Fig. $2 b)$. There were small differences in chemical shifts that we had expected from the disruption of the dimer interface (Supplementary Fig. 2b,c).

We determined the crystal structures of PHF20 Tudor1 and PHF20 Tudor2 to resolutions of $1.93 \AA$ and $2.0 \AA$, respectively (Fig. 2 and Table 1). PHF20 Tudor2 is a homodimer with Cys96 and Cys 100 of subunit A forming disulfide bonds with Cys 100 and Cys96 of subunit B, respectively (Fig. 2b). The lack of signal duplication in the ${ }^{1} \mathrm{H}_{-}{ }^{15} \mathrm{~N}$ HSQC spectrum of PHF20 Tudor2 dimer indicates that only one of two possible sets of disulfide bonds is formed, consistent with a specific dimer. Each subunit consists of five $\beta$-strands and one $3_{10}$-helix, and has a $\beta$-barrel fold characteristic of the Tudor domain. The dimer interface is made up of nine residues (Cys96, Trp97, Ser98, Asp99, Cys100, Phe102, Val108, Lys109 and His112) and buries a surface area of $670 \AA^{2}$. Five residues (Trp97, Tyr103, Phe120, 
Val124 and Asp122) form an enclosure reminiscent of the dimethyllysine binding cage of 53BP1 (ref. 13), with the possibility of van der Waals and cation $\pi$ contacts between aromatic rings and a methylammonium group (Fig. 2c). As is the case for the tandem Tudor domains in 53BP1, the side-chain carboxylate of Asp122 in PHF20 Tudor2 faces into the hydrophobic pocket, an orientation that would favor formation of a hydrogen bond with the amino proton of a dimethylated lysine. Using NMR chemical shift perturbation, we found that both the dimeric and monomeric forms of PHF20 Tudor2 bind p53K370me2 or p53K382me2 peptides. Individual affinities were weak but large affinity enhancement resulted upon simultaneous recognition of p53K370me2 and p53K382me2 as explained below.

The structure of PHF20 Tudor1 revealed a characteristic Tudor fold similar to that of PHF20 Tudor2 (Fig. 2d). PHF20 Tudor1 retained three aromatic side chains (Tyr29, Phe47 and Tyr54) and an aspartate (Asp23) that form a cage, but this cavity was blocked by a tryptophan (Trp50), making it unlikely that this Tudor domain would bind a methylated lysine (Fig. 2d). In contrast to the case in PHF20 Tudor1, the first Tudor domain of PHF20L1 specifically bound a p53K382me1 peptide (Fig. 1b). The structure of PHF20L1 Tudor1 revealed a canonical methyllysine binding cage (data not shown).

\section{PHF20 Tudor2 recognition of p53K370me2 and p53K382me2}

To verify that the cage identified in PHF20 Tudor2 can accommodate the dimethylated Lys 370 or Lys 382 , we prepared four chimeric proteins by linking p53 sequences to the $\mathrm{N}$ terminus (N-terminally linked constructs) or $\mathrm{C}$ terminus (C-terminally linked constructs) of mPHF20 Tudor 2 and chemically converting Cys 370 or Cys382 of linked p53 into dimethyllysine analogs $\mathrm{K}_{\mathrm{C}} 370 \mathrm{me} 2$ or $\mathrm{K}_{\mathrm{C}} 382 \mathrm{me} 2$, respectively. Provided that the stereochemical orientation of p53 and PHF20 in the fused constructs did not preclude binding, we expected that tethering the partner molecules would enhance their strength of association to a level where structure determination might be possible.

We compared the ${ }^{1} \mathrm{H}_{-}{ }^{15} \mathrm{~N}$ HSQC spectra recorded for the conversion of Cys 370 or Cys 382 to $\mathrm{K}_{\mathrm{C}} 370 \mathrm{me} 2$ or $\mathrm{K}_{\mathrm{C}} 382 \mathrm{me} 2$ in the four chimeric proteins to the titration spectra of mPHF20 Tudor2 with $\mathrm{p} 53 \mathrm{~K}_{\mathrm{C}} 370 \mathrm{me} 2$ or $\mathrm{p} 53 \mathrm{~K}_{\mathrm{C}} 382 \mathrm{me} 2$ peptides (Fig. 3 ). The ${ }^{1} \mathrm{H}_{-}{ }^{15} \mathrm{~N}$ HSQC spectra of mPHF20 Tudor 2 in the chimeric proteins before dimethylation are virtually identical to those of mPHF20 Tudor2 before any peptide addition (data not shown). After dimethylation, we observed major changes in chemical shifts for the two C-terminally linked constructs PHF20 Tudor2-p53K $\mathrm{C}_{\mathrm{C}} 370 \mathrm{me} 2$ and PHF20 Tudor2-p53K $382 \mathrm{me} 2$ (Fig. 3c,d) and smaller changes for the $\mathrm{N}$-terminally linked constructs $\mathrm{p} 53 \mathrm{~K}_{\mathrm{C}} 370 \mathrm{me} 2-\mathrm{PHF} 20$ Tudor 2 and p53 $\mathrm{K}_{\mathrm{C}} 382 \mathrm{me} 2-\mathrm{PHF} 20$ Tudor2 (Fig. 3e,f). This indicates that an interaction between the Tudor domain and the linked p53 fragment only occurs after formation of $\mathrm{K}_{\mathrm{C}} 370 \mathrm{me} 2$ or $\mathrm{K}_{\mathrm{C}} 382 \mathrm{me} 2$ and that the relative orientation of the Tudor domain and $\mathrm{p} 53$ peptide enforced by the $\mathrm{C}$-terminal linkage is favored. The extent of chemical shift changes in the fusion proteins for the $\mathrm{C}$ - and $\mathrm{N}$-terminally linked constructs is equivalent to adding more than 80 fold and about fourfold excess of methylated p53 peptides to mPHF20 Tudor2, respectively. The directions of perturbations upon dimethylation of the $\mathrm{C}$-terminally linked complexes are similar to those in the titrations of mPHF20 Tudor with $\mathrm{p} 53 \mathrm{~K}_{\mathrm{C}} 370 \mathrm{me} 2$ or $\mathrm{p} 53 \mathrm{~K}_{\mathrm{C}} 382 \mathrm{me} 2$ peptides (Fig. 3a,b), consistent with similar modes of interactions.

To test the specificity for dimethylation over trimethylation, we collected ${ }^{1} \mathrm{H}^{-15} \mathrm{~N}$ HSQC spectra for the C-terminally linked PHF20 Tudor-p53C370 chimera before and after trimethylation (Supplementary Fig. 3). The chemical shift perturbations were extremely small compared to those seen with the dimethylation of PHF20 Tudor2-p53C370 or PHF20 Tudor2-p53C382 (Fig. 3), demonstrating that PHF20 Tudor2 did not recognize the trimethylated forms of p53. PHF20 Tudor2 did, however, recognize p53 monomethylated at 
Lys370 or at Lys382 but with lower affinity than dimethylated p53 (see below and Fig. $3 \mathrm{~g}, \mathrm{~h})$.

\section{NMR structure of mPHF20 Tudor2 fused to $\mathrm{p}^{2} 3 \mathrm{~K}_{\mathrm{C}} 370 \mathrm{me} 2$}

We determined the NMR structure of the high-affinity linked complex PHF20 Tudor2p53 $\mathrm{K}_{\mathrm{C}} 370 \mathrm{me} 2$ (Fig. $3 \mathrm{i}$ and Table 2). The NMR and crystal structures superimpose well with an r.m.s. deviation of $1.25 \AA$ for the backbone atoms $\mathrm{N}, \mathrm{C}^{\mathrm{a}}$ and $\mathrm{C}^{\prime}$ of PHF20 residues Asn90 to Phe136. In PHF20 Tudor2-p53K $370 \mathrm{me} 2$, the p53 sequence was rigid to a certain degree, as shown by the steady-state $\left\{{ }^{1} \mathrm{H}\right\}-{ }^{15} \mathrm{~N}$ heteronuclear nuclear Overhauser enhancement (NOE) measurements (Supplementary Fig. 4). As expected, $\mathrm{K}_{\mathrm{C}} 370 \mathrm{me} 2$ was surrounded by methyllysine binding cage residues Trp97, Tyr103, Phe120, Val124 and Asp122 of PHF20 (Fig. 3i). The carboxylate group of Asp122 contributed to favorable coulombic interaction with the dimethylammonium ion of $\mathrm{K}_{\mathrm{C}} 370 \mathrm{me} 2$ and was most likely involved in a hydrogen bond with the amino proton of $\mathrm{K}_{\mathrm{C}} 370 \mathrm{me} 2$, although this was not apparent in the NMR ensemble owing to a lack of NOE measurements between Asp122 and $\mathrm{K}_{\mathrm{C}} 370 \mathrm{me} 2$. Other residues of PHF20 Tudor2 (Arg101, Pro104, Tyr121 and Asp99) and p53 (His368, Leu369, Lys372 and Lys373) were involved in the interaction. Arg101 contacts His368; Pro104 and Tyr121 are part of a hydrophobic network with Leu369; Asp99 is close to Lys372, and Lys373 and could interact via charge-charge interactions. The area around the hydrophobic cage of mPHF20 Tudor 2 is predominantly negatively charged, complementing the positively charged lysines and dimethyllysine of p53 (Fig. 3i). The contacts observed between PHF20 and p53 in the structure of PHF20 Tudor2$\mathrm{p} 53 \mathrm{~K}_{\mathrm{C}} 370 \mathrm{me} 2$ are in agreement with the chemical shift perturbations resulting from dimethylation of PHF20 Tudor2-p53C370 or PHF20 Tudor2-p53C382, or from the titrations of PHF20 Tudor 2 or mPHF20 Tudor 2 with $\mathrm{p} 53 \mathrm{~K}_{\mathrm{C}} 370 \mathrm{me} 2$ or $\mathrm{p} 53 \mathrm{~K}_{\mathrm{C}} 382 \mathrm{me} 2$ peptides (Fig. 3a-f). Mutating Trp97 and Tyr103 in the methyllysine binding cage of PHF20 Tudor2-p53 $\mathrm{K}_{\mathrm{C}} 370 \mathrm{me} 2$ to alanines prevented complex formation while preserving the structure of PHF20 Tudor2 (data not shown). The W97A and Y103A mutations markedly decreased the interaction of PHF20 with p53 in the context of full-length proteins in cells as indicated below.

\section{PHF20-based sensors of lysine methylation}

The tight association of methylated p53 with PHF20 Tudor2 in the linked constructs makes these chimeric proteins potentially useful as sensors or reporters of lysine methylation. Indeed, treatment of PHF20 Tudor2-p53K370 and PHF20 Tudor2-p53K382 with the human lysine methyltransferases SMYD2 (ref. 28) and SET8 (refs. 29,30), respectively, in the presence of methyl donor $S$-adenosyl methionine led to changes in PHF20 chemical shifts, demonstrating methylation of p53K370 and p53K382 (Fig. 3g,h). The changes were less pronounced than those observed after chemical dimethylation of the linked constructs (Fig. 3c,d), consistent with monomethylation. SMYD2 and SET8 have previously been reported to specifically monomethylate p53 at Lys370 and Lys382, respectively ${ }^{3,5}$. Therefore, this NMR spectroscopy-based approach provides information not only on the site but also on the state of lysine methylation. Although NMR chemical shift perturbation procedures have been developed to investigate protein phosphorylation and acetylation in vitro and in cell extracts or even in living cells ${ }^{31-33}$, to our knowledge no procedure exists for detecting lysine methylation. This is because, unlike phosphorylation or acetylation, methylation does not perturb the backbone NMR signals of the modified residue. In the linked constructs, PHF20 has the role of a signal amplifier, giving rise to large changes in chemical shifts upon methylation of p53.

This simple methodology could be used to probe methylation or demethylation activity in cell extracts or in vivo after injection of the sensor constructs in living cells. Possible 
applications are the validation of predicted lysine methyltransferases or demethylases and the screening of small-compound inhibitors of these enzymes.

\section{Dual recognition of doubly dimethylated p53 by PHF20 Tudor2}

We used NMR spectroscopy to investigate whether the Tudor homodimer could simultaneously recognize the methylation sites Lys370 and Lys382 in p53. The titrations of ${ }^{15} \mathrm{~N}$-labeled PHF20 Tudor 2 with nonlabeled p53 peptides (amino acids 363-389) harboring single dimethylation ( $\mathrm{p}^{2} 3 \mathrm{~K}_{\mathrm{C}} 370 \mathrm{me} 2$ or $\mathrm{p} 53 \mathrm{~K}_{\mathrm{C}} 382 \mathrm{me} 2$ ) or double dimethylation $\left(\mathrm{p} 53 \mathrm{~K}_{\mathrm{C}} 370 \mathrm{me} 2 \mathrm{~K}_{\mathrm{C}} 382 \mathrm{me} 2\right)$ led to perturbation of the same signals in the ${ }^{1} \mathrm{H}_{-}{ }^{15} \mathrm{~N}$ HSQC spectrum of PHF20 Tudor2, demonstrating a conserved binding interface for the three peptides (data not shown). Although the exchange between free and PHF20 Tudor2-bound peptide was fast on the time scale of NMR chemical shifts when only Lys370 or Lys382 is dimethylated, the exchange was intermediate when these two sites are both dimethylated (Fig. 4a). This suggests enhanced avidity through multivalent recognition of $\mathrm{K}_{\mathrm{C}} 370 \mathrm{me} 2$ and $\mathrm{K}_{\mathrm{C}} 382 \mathrm{me} 2$ by PHF20 Tudor2. These results are consistent with the complementary titrations of p53 peptides, specifically ${ }^{13} \mathrm{C}$-labeled at the methyl groups of $\mathrm{K}_{\mathrm{C}} 370 \mathrm{me} 2$ and $\mathrm{K}_{\mathrm{C}} 382 \mathrm{me}$ 2, with unlabeled PHF20 Tudor2 dimer (Fig. 4b). There was no marked shift in the ${ }^{13} \mathrm{C}$ methyl signals of all three $\mathrm{p} 53$ peptides but there was progressive decrease in signal intensities during the titration, indicative of intermediate exchange on the time scale of NMR chemical shifts (Fig. 4b). Signal disappearance was fastest when the two sites were both dimethylated compared to when either site was dimethylated in an equimolar mixture of $553 \mathrm{~K} 370 \mathrm{me} 0 \mathrm{~K}_{\mathrm{C}} 382 \mathrm{me} 2$ and $\mathrm{p} 53 \mathrm{~K}_{\mathrm{C}} 370 \mathrm{me} 2 \mathrm{~K} 382 \mathrm{me} 0$, in agreement with a gain in apparent affinity brought about by the dual recognition mode. Strongly supporting this interpretation, the decrease in ${ }^{1} \mathrm{H}_{-}^{-13} \mathrm{C}$ me2 NMR signal intensities was the same when $\mathrm{p} 53 \mathrm{~K}_{\mathrm{C}} 370 \mathrm{me} 2 \mathrm{~K}_{\mathrm{C}} 382 \mathrm{me} 2$ or the equimolar mixture $\mathrm{p} 53 \mathrm{~K} 370 \mathrm{me} 0 \mathrm{~K}_{\mathrm{C}} 382 \mathrm{me} 2$ and p53K $\mathrm{C}_{\mathrm{C}} 370 \mathrm{me} 2 \mathrm{~K} 382 \mathrm{me} 0$ peptides were used for titrations with mPHF20 Tudor2 (Fig. 4b). As an additional control, we also examined possible double recognition of $\mathrm{p} 53 \mathrm{~K}_{\mathrm{C}} 372 \mathrm{me}^{2} \mathrm{~K}_{\mathrm{C}} 382 \mathrm{me} 2$ by the PHF 20 Tudor 2 dimer. The distance separating Lys 372 from Lys382 is in principle long enough to allow the simultaneous recognition of K372me2 and K382me 2 by the two aromatic cages of PHF20 Tudor2 dimer. We know that a p53K372me2 peptide can interact with PHF20 Tudor2 but exhibits markedly weaker binding compared to p53K370me2 or p53K382me2 peptides (Supplementary Fig. 1). As shown by the NMR titration of PHF20 Tudor 2 dimer with p $53 \mathrm{~K}_{\mathrm{C}} 372 \mathrm{me}^{2} \mathrm{~K}_{\mathrm{C}} 382 \mathrm{me} 2$, we observed no affinity enhancement (Supplementary Fig. 5a).

By quantifying the gain in affinity owing to dual recognition, we determined an apparent $K_{\mathrm{d}}$ of $99.0 \pm 15.7 \mu \mathrm{M}$ using isothermal titration calorimetry (ITC) for the interaction of PHF20 Tudor 2 dimer with the $\mathrm{p} 53 \mathrm{~K}_{\mathrm{C}} 370 \mathrm{me}^{2} 2 \mathrm{~K}_{\mathrm{C}} 382 \mathrm{me} 2$ peptide. The stoichiometry parameter $(n)$ is close to unity $(n=0.93 \pm 0.29$ ( \pm s.d.) ), indicating that one dimeric protein binds one doubly dimethylated peptide. It is important to note that the strength of interaction is underestimated because a methyllysine analog leads to a $K_{\mathrm{d}}$ incrase by $\sim 100-200 \%$ compared to that for a real methyllysine ${ }^{34}$ (unpublished data). Therefore, the true $K_{\mathrm{d}}$ achieved from the double recognition mode of PHF20 Tudor2 is expected to be lower than $50 \mu \mathrm{M}$, which is the same affinity range as for other methylated peptide-binding domains such as the tandem Tudor domains of 53BP1. Under identical conditions, we detected no marked ITC signal when we titrated mPHF20 Tudor 2 with $\mathrm{p} 53 \mathrm{~K}_{\mathrm{C}} 370 \mathrm{me} 2 \mathrm{~K}_{\mathrm{C}} 382 \mathrm{me} 2$ (Fig. 4c). These results from ITC experiments are in agreement with those from NMR spectroscopy, where we obtained high $K_{\mathrm{d}}$ values of $4.6 \pm 0.6 \mathrm{mM}$ and $3.5 \pm 0.5 \mathrm{mM}$ for the binding of the $\mathrm{p} 53 \mathrm{~K}_{\mathrm{C}} 370 \mathrm{me} 2 \mathrm{~K} 382 \mathrm{me} 0$ and $\mathrm{p} 53 \mathrm{~K} 370 \mathrm{me} 0 \mathrm{~K}_{\mathrm{C}} 382 \mathrm{me} 2$ peptides to $\mathrm{mPHF} 20$ Tudor2, respectively (Supplementary Fig. 5b). The gain in affinity from dual recognition by PHF20 Tudor2 dimer was $\sim 50$-fold. 
We could not crystallize the PHF 20 Tudor $2-53 K_{C} 370 m^{2} 2 K_{C} 382 m e 2$ complex. However, we generated a model of the complex in docking calculations combining information from the NMR spectroscopy structure of the PHF20 Tudor2-p53K $\mathrm{C}_{\mathrm{C}} 370 \mathrm{me} 2$ complex, the crystal structure of dimeric PHF20 Tudor2 and the NMR spectroscopy-based titration of PHF20 Tudor 2 with a $\mathrm{p} 53 \mathrm{~K}_{\mathrm{C}} 370 \mathrm{me} 2 \mathrm{~K}_{\mathrm{C}} 382 \mathrm{me} 2$ peptide. From the model, the doubly dimethylated p53 peptide fit nicely in a groove formed between the two Tudor domains in the homodimer opposite the two disulfide bonds (Fig. 4d). The $\sim 25 \AA$ distance separating the two methylated sites, $\mathrm{p} 53 \mathrm{~K}_{\mathrm{C}} 370 \mathrm{me} 2$ and $\mathrm{p} 53 \mathrm{~K}_{\mathrm{C}} 382 \mathrm{me} 2$, is optimal for their simultaneous recognition by the two binding cages of PHF20 Tudor2. Therefore, specificity and tighter binding are determined by an optimal dual recognition of the two methylated sites in p53.

\section{PHF20 stabilizes p53 by inhibiting p53 ubiquitylation}

To probe the importance of p53 methylation for the PHF20-p53 interaction in vivo, we checked whether mutations that affect the interaction of PHF20 Tudor2 with p53K370me2 or p53K382me 2 peptides but preserve the Tudor domain fold would alter the affinity of PHF20 for p53 in the context of full-length proteins. The W97A or Y103A mutations in the methyllysine binding cage of PHF20 both markedly diminished the affinity of PHF20 for p53 in cells (Fig. 5a). To begin to address the functional importance of the PHF20-p53 complex, we then checked whether PHF20 would affect the stability of p53. Ubiquitylation of p53 by the ubiquitin ligase Mdm2 has an essential regulatory role in that it controls p53 nuclear export and degradation ${ }^{35}$. The majority of $\mathrm{p} 53$ sites ubiquitylated by $\mathrm{Mdm} 2$ are located at its C terminus (for example, Lys370, Lys372, Lys373, Lys381, Lys382 and Lys 386$)^{36}$, precisely where PHF20 binds p53. Furthermore, both the $\mathrm{N}$ - and the C-terminal regions of p53 have been implicated in direct contacts with Mdm2 (ref. 37). Therefore, the direct PHF20-p53 interaction would likely prevent or diminish ubiquitylation. Consistent with this possibility, a pulse-chase assay showed that the degradation of p53 was decreased in HCT 116 cells transfected with plasmid encoding PHF20 (Fig. 5b). Furthermore, Mdm2mediated ubiquitylation of 533 was reduced in the presence of PHF20 (Fig. 5c). This protection by PHF20 was diminished when the methyllysine binding cage of PHF20 was mutated to prevent interaction with p53K370me2 and p53K382me2 (Supplementary Fig. $6 \mathrm{a}, \mathrm{b})$. It is therefore likely that dimethylation of p53 at Lys370 or Lys382 or at both sites acts as a molecular switch that diminishes $\mathrm{p} 53$ ubiquitylation by triggering a direct interaction with PHF20 that blocks Mdm2 from accessing p53.

\section{PHF20 contributes to p53 upregulation after DNA damage}

To determine whether PHF20 might regulate stress-induced p53 expression, we knocked down PHF2O using small interfering RNA (siRNA) before challenging HCT 116 cells with the genotoxic agents doxorubicin or etoposide. Knockdown of $P H F 2 O$ substantially reduced the p53 levels induced by doxorubicin or etoposide in wild-type TP53 but not in TP53-null HCT 116 cells (Fig. 6a,b). We verified that the two genotoxic agents also induced phosphorylation of p53 at Ser15, a key phosphorylation target during p53 activation (Fig. $6 \mathrm{~b})$. Consistent with the reduced expression of p53, the levels of $\mathrm{p} 21$ and Bax proteins were also decreased (Fig. 6a). Moreover, a chromatin immunoprecipitation (ChIP) assay showed that binding of $\mathrm{p} 53$ to the $\mathrm{p} 21$ promoter was considerably reduced by knockdown of PHF2O (Fig. 6c). These results indicate that PHF20 contributes to the upregulation of p53 expression in response to genotoxic stress.

\section{Ectopic expression of PHF20 activates p53}

We checked whether ectopic expression of p53 in different cell lines would lead to phenotypic changes that are consistent with p53 activation. We prepared stable MCF7 Tetoff (wild-type TP53), HCT 116 (wild-type TP53) and HCT 116 TP53-null cell lines expressing Flag-tagged PHF20 or PHF20 (Fig. 7a). Then we evaluated cell growth, DNA 
synthesis, cell survival and cell-cycle progression using eight clonal cell lines for each transfectant. Cell growth was clearly inhibited by ectopic expression of PHF20 in cells expressing wild-type p53 (Fig. 7b). Similarly, DNA synthesis was repressed by PHF20 as shown from reduced $\left[{ }^{3} \mathrm{H}\right]$ thymidine incorporation when PHF20 was expressed (Fig. 7c). Cell death by doxorubicin or etoposide was $\sim 40 \%$ enhanced upon expression of PHF20 (Fig. 7d). In cells synchronized with nocodazole treatment, induction of PHF20 led to delayed cell-cycle transitions from G1 to S and M to G1 phases (Fig. 7e and Supplementary Fig. $6 c, d)$. We obtained similar results with stably transfected A2780S (wild-type TP53) and A2780CP (mutated TP53) cell lines (data not shown). Therefore, we conclude that PHF20 regulates cell proliferation and survival, as well as G1-S and G2-M cell-cycle checkpoints, which are hallmarks of p53 activation.

\section{DISCUSSION}

In this study we showed that PHF20 forms a complex with p53 in human cells and that this interaction is dependent on a functional Tudor domain that drives a methyllysine-dependent protein-protein interaction. The second Tudor domain of PHF20 interacts specifically with p53 peptides monomethylated or dimethylated at Lys 370 or Lys382. The dissociation constants for these interactions are in the millimolar range, which is not uncommon for isolated methyllysine or methylarginine recognition domains probed with peptides $34,38,39$. These domains often belong to modular proteins involved in combinatorial interactions giving rise to effective tight associations ${ }^{40-42}$. PHF20 is modular, harboring five recognizable domains, including two Tudor domains, a PHD finger as well as an AT hook and $\mathrm{C}_{2} \mathrm{H}_{2}$-type zinc finger, which both are putative DNA-binding domains. Indeed, it was recently shown that PHF20 specifically binds DNA ${ }^{17}$. PHF20 is a subunit of the NSL complex containing the enzymes MOF lysine acetyltransferase and OGT1 known to modify p53 (refs. 18-22). It is therefore likely that in the cellular environment, PHF20 participates in simultaneous multiple interactions with other proteins or DNA.

Combinatorial interactions may also occur owing to PHF20 dimerization. PHF20 Tudor2 forms a bis-disulfide cross-linked homodimer that participates in a divalent interaction with methylated p53 in vitro. We determined that substantial affinity with an apparent $K_{\mathrm{d}}$ in the micromolar range, comparable to that of 53BP1 tandem Tudor domains, is achieved when p53 is dimethylated at two sites (Lys370 and Lys382), with each methyllysine being recognized by a different Tudor domain of the PHF20 Tudor2 homodimer. This finding provides a proof of principle of enhanced specificity and selectivity by double methyllysine recognition. Binding to two methylated lysines has also been shown for the lysine demethylase PHF8, which associates with H3K4me3 and H3K9me2 via a PHD finger and the catalytic jumonji domain, respectively ${ }^{43}$.

Although PHF20 Tudor2 and Tudor1-2 proteins purified from overexpression in Escherichia coli are dimeric, it is not known whether a PHF20 homodimer forms in the nucleus of eukaryotic cells. This is, however, plausible as there are nuclear proteins that dimerize via disulfide bonds. For example, the mammalian E2A transcription factor homodimer is regulated by formation of an intermolecular disulfide bond necessary for high-affinity DNA binding in $\mathrm{Vivo}^{44}$. A pair of disulfide bonds like in PHF20 Tudor2 homodimer is expected to have a more negative overall redox potential than a single disulfide bond and therefore more resistance to reduction in cells. Dimerization via disulfide bonds also offers the possibility of redox control of the PHF20-methylated p53 complex. The observed coimmunoprecipitations of differently tagged full-length PHF20 from cellular extracts supports the possibility that PHF20 homodimerizes in cells (Supplementary Fig. 7). 
Our data strongly suggest that the interaction of PHF20 with p53K370me1/2 or p53K382me1/2 or both stabilizes p53 by preventing Mdm2-mediated ubiquitylation. The p53 ubiquitylation sites overlap with the binding area covered by PHF20 Tudor2, likely explaining the stabilization of p53 by PHF20. Previous studies have shown that dimethylation of $\mathrm{p} 53$ at Lys370 promotes p53-activated transcription but the mechanism for such activation is not known ${ }^{4}$. Protection of $\mathrm{p} 53$ from degradation by dimethylation of Lys 370 may partly explain this finding. Furthermore, we showed that activation of p53 by PHF20 is enhanced in response to DNA damage. This may be due to the demonstrated increased p53 dimethylation at Lys382 with DNA damage ${ }^{6,7}$.

The ubiquitylation of p53 by Mdm2 is regulated by the Akt kinase, which stimulates the translocation of Mdm2 from the cytoplasm to the nucleus, where it binds p53 and drives its degradation ${ }^{45}$. Akt also phosphorylates PHF20 at Ser291, leading to PHF20 translocation from the nucleus to the cytoplasm ${ }^{17}$. Therefore, the opposite directionality Akt-triggered Mdm2 and PHF20 translocations and antagonistic functions of Mmd2 and PHF20 synergistically contribute to $\mathrm{p} 53$ regulation.

\section{ONLINE METHODS}

\section{Protein domain microarrays}

Fabrication methods for protein domain microarrays and peptide labeling have been described previously ${ }^{12}$.

\section{Preparation of proteins and peptides}

DNA encoding PHF20 Tudor1 (amino acids 1-83 and 4-69), PHF20 Tudor2 (amino acids 84-147), PHF20 Tudor1-2 (amino acids 1-147), mPHF20 Tudor2, mPHF20 Tudor2 N- or C-terminally linked to p53 segments, SET8 (amino acids 172-352) and SMYD2 (amino acids 1-282) were incorporated in a modified pET15b vector (Novagen) encoding tobacco etch virus (TEV) protease-cleavable $\mathrm{N}$-terminal histidine tag. Mutations were generated using QuikChange (Stratagene). Proteins were overexpressed in E. coli Rosetta (DE3) pLysS cells cultured in LB medium or in ${ }^{15} \mathrm{~N}$-enriched or ${ }^{15} \mathrm{~N}$ - and ${ }^{13} \mathrm{C}$-enriched M9 medium prepared as reported previously ${ }^{46}$. Cells were grown to $D_{600 \mathrm{~nm}} \sim 0.8$ at $37^{\circ} \mathrm{C}$ and induced with IPTG at $15{ }^{\circ} \mathrm{C}$ for $16-20 \mathrm{~h}$. Cells were collected, lyzed using an Emulsiflex C-5 high-pressure homogenizer (Avestin) and centrifuged. Proteins in the supernatant were purified by $\mathrm{Ni}^{2+}$-NTA affinity chromatography (Qiagen) and, after TEV protease treatment overnight at $4{ }^{\circ} \mathrm{C}$, by Superdex 75 size exclusion chromatography (GE Healthcare).

Nonlabeled, ${ }^{15} \mathrm{~N}$-labeled and ${ }^{15} \mathrm{~N}$ - and ${ }^{13} \mathrm{C}$-labeled lysine-methylated $\mathrm{p} 53$ peptides were prepared via expression in Escherichia coli as C-terminal fusion to hexahistidine-GB1, chemical installation of methyllysine analog, cleavage of hexahistidine-GB1 by TEV protease and purification by Superdex 75 size-exclusion chromatography and preparative C18 reversed-phase chromatography (Phenomenex). The method for preparing peptides or proteins harboring a methyllysine analog was published previously ${ }^{11,47}$.

\section{X-ray crystallography}

Crystals of PHF20 Tudor 1 were grown at $22{ }^{\circ} \mathrm{C}$ using the hanging-drop vapor-diffusion method by mixing $2 \mu \mathrm{l}$ of protein solution at $2 \mathrm{mg} \mathrm{ml}^{-1}$ in acidified water (pH 5.0) and $2 \mu \mathrm{l}$ or reservoir solution containing $0.1 \mathrm{M}$ cacodylic acid, $\mathrm{pH} 4.0,0.2 \mathrm{M}$ ammonium acetate and 28\% (w/v) PEG 3000. Crystals formed within $48 \mathrm{~h}$, were soaked in the reservoir solution with $5 \%(\mathrm{v} / \mathrm{v})$ glycerol and quick-frozen in liquid nitrogen. 
Crystals of PHF20 Tudor 2 were grown similarly mixing $2 \mu 1$ of protein solution at $2 \mathrm{mg}$ $\mathrm{ml}^{-1}$ in $50 \mathrm{mM}$ Tris-HCl, $\mathrm{pH} 8.0$ and $2 \mu \mathrm{l}$ of reservoir solution containing $0.1 \mathrm{M}$ Tris- $\mathrm{HCl}$, $\mathrm{pH} 8.5,12 \%$ (w/v) PEG 8000. Crystals formed within 1-3 weeks and were cryoprotected with reservoir solution plus $30 \%$ (v/v) glycerol.

X-ray diffraction data for PHF20 Tudor1 were collected at 100K using a Rigaku MSC CuKa MicroMax-007 diffractometer at a wavelength of $1.5418 \AA$. Crystals formed in space group $P 2_{1}$ with two molecules of PHF20 Tudor1 per asymmetric unit. Data for PHF20 Tudor 2 were collected at $100 \mathrm{~K}$ at the Advance Photon Source 19-BM beamline. Wavelength was $0.992349 \AA$ A. Crystals formed in space group $\mathrm{P}_{3}$ with one molecule of PHF20 Tudor2 dimer per asymmetric unit. Data were processed using HKL2000 (ref. 48).

Phases were obtained by molecular replacement with models of PHF20 Tudor1 and PHF20 Tudor2 generated using the amino acid sequences and the server Phyre with default parameters ${ }^{49}$. Model building was completed with $\operatorname{Coot}^{50}$. Model refinement was carried out to resolutions of $1.93 \AA$ and $2.0 \AA$ for PHF20 Tudor1 and Tudor2, respectively, with Phenix ${ }^{51}$. For PHF20 Tudor2, noncrystallographic symmetry restraints were enforced between the two Tudor domains in the asymmetric unit until the $R_{\text {free }}$ dropped below $28 \%$, then removed for additional refinement. Secondary structure restraints determined by Phenix were used in refinements. Weighting between X-ray and geometric gradients were allowed to be automatically determined by Phenix. Data collection and refinement statistics are listed in Table 1.

\section{NMR spectroscopy and NMR structure determination}

NMR experiments were performed at $25^{\circ} \mathrm{C}$ using $600 \mathrm{MHz}$ and $700 \mathrm{MHz}$ Bruker Avance III spectrometers with cryoprobes. NMR data were processed and analyzed with NMRPipe $^{52}$ and NMRView ${ }^{53}$. Protein samples were in $25 \mathrm{mM}$ sodium phosphate buffer, $\mathrm{pH} 7.5,1.5 \mathrm{mM} \mathrm{NaN}_{3}, 0.3 \mathrm{mM}$ DSS, $10 \% \mathrm{D}_{2} \mathrm{O}$ and $90 \% \mathrm{H}_{2} \mathrm{O}$. Protein and peptide concentrations were $0.2-15 \mathrm{mM}$.

Standard NMR experiments were recorded including two-dimensional (2D) ${ }^{1} \mathrm{H}_{-}{ }^{15} \mathrm{~N}$ and ${ }^{1} \mathrm{H}_{-}{ }^{13} \mathrm{C}$ HSQC, (HB)CB(CGCD)HD and (HB)CB(CGCDCE)HE, 3D HNCACB, $\mathrm{CBCA}(\mathrm{CO}) \mathrm{NH}, \mathrm{HNCO}, \mathrm{HN}(\mathrm{CA}) \mathrm{CO}, \mathrm{HBHA}(\mathrm{CO}) \mathrm{NH}$ and $\mathrm{CCH}-\mathrm{TOCSY}$ for resonance assignments of PHF20 Tudor2-p53K $\mathrm{K}_{\mathrm{C}} 370 \mathrm{me} 2$ and $\mathrm{p} 53$ peptides. To assess dynamic properties of free and $\mathrm{p} 53 \mathrm{~K}_{\mathrm{C}} 370 \mathrm{me} 2$-linked PHF20 Tudor2, steady-state $\left\{{ }^{1} \mathrm{H}\right\}^{-15} \mathrm{~N}$ heteronuclear NOEs were determined as a ratio of cross-peak intensities in experiments recorded with and without amide ${ }^{1} \mathrm{H}$ saturation for $3 \mathrm{~s}$ prior to the ${ }^{15} \mathrm{~N}$ excitation pulse. NOE-based distance restraints were derived from $3 \mathrm{D}^{15} \mathrm{~N}$ NOESY-HSQC and aliphatic and aromatic ${ }^{13} \mathrm{C}$ NOESY-HSQC spectra. Hydrogen bonds were derived from ${ }^{1} \mathrm{H}-{ }^{2} \mathrm{H}$ exchange experiments. NOE assignment was facilitated using SANE ${ }^{54}$. Restraints for backbone angles $\varphi$ and $\psi$ were derived from TALOS ${ }^{55}$ and $\mathrm{CSI}^{56}$ analysis while $\chi 1$ angle restraints were determined based on NOE intensities.

Initially, 200 structures were calculated with the simulated annealing protocol of CYANA ${ }^{57}$. Violations and NOE assignments were analyzed with SANE. Several CYANA and SANE iterations were done until distance and angle violations were below $0.3 \AA$ and $5^{\circ}$, respectively. One hundred lowest energy structures were refined with $\mathrm{AMBER}^{58}$ in a 30-ps 30,000 -step 1,000K simulated annealing protocol with the generalized Born continuum solvent model. The final 20 structures with the lowest AMBER energies were selected for PROCHECK-NMR ${ }^{59}$ analysis and statistics analysis. The structural statistics are summarized in Table 2. Structure representations were created with MOLMOL ${ }^{60}$ and PyMOL (http://www.pymol.org/). 


\section{Isothermal titration calorimetry}

Samples were in Tris- $\mathrm{HCl}, \mathrm{pH} 7.5,50 \mathrm{mM} \mathrm{NaCl}$. Measurements were done at $10^{\circ} \mathrm{C}$ using a VP-isothermal titration calorimeter (MicroCal). The protein and peptide concentrations were 50-200 $\mu \mathrm{M}$ and 2-4 mM, respectively. Data were processed and analyzed using Origin (OriginLab).

\section{Fluorescence images}

MCF7 cells grown on cover slips were transfected with pEGFP-PHF20 full-length or pEGFP-PHF20 Tudor1-2 using Lipofectamine 2000 (Invitrogen). Twenty-four hours after transfection, cells were washed with PBS, fixed in $2 \%(\mathrm{v} / \mathrm{v})$ formaldehyde for $10 \mathrm{~min}$ at room temperature, washed with PBS containing $0.1 \%$ (w/v) NP-40 and treated with $50 \mathrm{mg}$ $1^{-1}$ DAPI for $5 \mathrm{~min}$. After three more washes, cells were mounted in glycerol-containing SlowFade reagent (Invitrogen). Imaging was performed using a confocal microscope.

\section{Co-immunoprecipitation assays}

Two $90 \%$ confluent 10 -cm plates of HEK 293 cells were transfected with pEGFP or pEGFP-PHF20 Tudor1-2 using Lipofectamine 2000. Forty hours after transfection, cells were collected in $500 \mathrm{ml}$ of ice-cold mild buffer (MB, $10 \mathrm{mM}$ Tris-HCl, pH 7.5, 1\% (w/v) Triton X-100, $150 \mathrm{mM} \mathrm{NaCl}, 5 \mathrm{mM}$ EDTA and protease inhibitor tablet from Roche), sonicated for $10 \mathrm{~s}$ on $20 \%$ power and centrifuged. Supernate was used for co-IP, saving $10 \%$ to evaluate protein input. To make the immunoprecipiation beads, protein A/G-UltraLink beads (Thermo Scientific) were washed in MB, then incubated with $3 \mu$ lanti-GFP antibody (Invitrogen, A-6455, used at 1:200 dilution) in $500 \mu 1 \mathrm{MB}$ for $4 \mathrm{~h}$ at $4{ }^{\circ} \mathrm{C}$. Beads were washed $2 \times$ in $\mathrm{MB}$ and cell lysate was added and mixed at $4{ }^{\circ} \mathrm{C}$ overnight. Beads were washed $4 \times$ in $\mathrm{MB}$ and boiled in $45 \mu 1$ loading buffer to release the bound proteins. The lysate input and co-immunoprecipatated proteins were analyzed by western blot using monoclonal antibodies anti-GFP (Covance, MMS-118p, used at 1:1,000 dilution) and antip53 (Santa Cruz, clone D01 sc-126, used at 1:1,000 dilution).

\section{Cell culture and transfection}

HEK 293, MCF7, HeLa and HCT 116 cell lines were obtained from ATCC and cultured in Dulbecco's modified Eagle's medium containing 10\% FBS. Lipofectamine plus (Invitrogen) was used for transfections.

\section{Effect of PHF20 on cell proliferation and viability}

Cells transfected with a PHF20-encoding pcDNA3 plasmid or empty pcDNA3 plasmid were plated on 35-mm dishes at a density of $1.0 \times 10^{5}$ cells/dish in Dulbecco's modified Eagle's medium with $10 \%$ FBS. The number of cells at $24 \mathrm{~h}, 48 \mathrm{~h}$ and $72 \mathrm{~h}$ was determined using a cell counter (Coulter) and a colorimetric-based CellTiter96 AQueous cell proliferation assay (Promega). Cell viability was examined with Trypan blue staining following treatment of cells with $1 \mu \mathrm{M}$ doxorubicin or $100 \mu \mathrm{M}$ etoposide.

\section{Effect of PHF20 on DNA synthesis}

Cells were grown to $80 \%$ confluence in six-well plates and treated with ${ }^{3} \mathrm{H}$-enriched thymidine $\left(5 \mathrm{Ci} \mathrm{ml}^{-1}\right)$ during the last $16 \mathrm{~h}$ of growth. Cells were rinsed $2 \times$ with ice-cold serum-free culture medium and incubated twice with $5 \mathrm{ml}$ of $10 \%$ TCA for $10 \mathrm{~min}$ on ice before lysis in a $500 \mu \mathrm{l}$ solution of $0.3 \mathrm{~N} \mathrm{NaOH}$ and $1 \%$ SDS for $30 \mathrm{~min}$ at $37^{\circ} \mathrm{C}$. Incorporated radioactivity was quantified by liquid scintillation counting. 


\section{RNA interference (RNAi)}

RNAi duplexes were synthesized by Dharmacon. The cDNA-targeted region and the sequence of PHF2O siRNA duplexes were: AAGAGGAUGGAUCUUCUGAAU and AAAGCAUUGGAGGAGGAUAAU. RNAi duplexes were reconstituted to $20 \mu \mathrm{M}$ in sterile RNase-free water. Transfection of siRNA for targeting of endogenous genes was performed using oligofectamine reagent (Invitrogen).

\section{Flow cytometry and cell-cycle analysis}

PHF20 plasmid-transfected MCF7 Tet-off cells were cultured in doxycycline-free medium for $12 \mathrm{~h}$ and then treated with $40 \mathrm{ng} \mathrm{ml}^{-1}$ nocodazole for $12 \mathrm{~h}$ to synchronize cells in $\mathrm{M}$ phase. Cells were washed and cultured in fresh medium without nocodazole for different durations. Cells were fixed in prechilled $70 \%$ ethanol for $2 \mathrm{~h}$, washed with PBS, resuspended in propidium iodide (PI) staining solution $\left(20 \mu \mathrm{g} \mathrm{ml}^{-1} \mathrm{PI}\right.$ in PBS, $0.1 \%$ Triton $\mathrm{X}-100$ and $0.2 \mathrm{mg} \mathrm{ml}^{-1}$ DNase-free RNase A) for $15 \mathrm{~min}$ at $37^{\circ} \mathrm{C}$ and then analyzed by flow cytometry. DNA content histograms and fluorescence-activated cell sorting data were analyzed using FlowJo.

\section{In vivo ubiquitylation assay}

H1299 cells were co-transfected with plasmids encoding wild-type HA-p53, Flag-PHF20, Myc-ubiquitin and Mdm2, and then treated with $50 \mu \mathrm{M}$ of proteasome inhibitor MG132 (Sigma) for $2 \mathrm{~h}$ before collecting the cells. After two washes with ice-cold PBS, cells were lysed in $50 \mathrm{mM}$ Tris-HCl, pH 7.4, $150 \mathrm{mM} \mathrm{NaCl}, 1 \mathrm{mM}$ EDTA, $1 \%$ Triton X-100, 10\% glycerol and protease inhibitors. Cell lysates were immunoprecipitated with an anti-HA antibody and then blotted with an anti-Myc antibody. Ubiquitylation assays were also done in MCF7 cells in the context of endogeneous wild-type p53 (Supplementary Fig. 6b).

\section{Supplementary Material}

Refer to Web version on PubMed Central for supplementary material.

\section{Acknowledgments}

We acknowledge the use of beamline 19-BM at the Advanced Photon Source (APS), Argonne National Laboratory. APS is operated by UChicago Argonne, LLC, for the US Department of Energy under contract DEAC02-06CH11357. We are grateful to Y. Kim at APS for assistance with X-ray data collection. We acknowledge the help of A. Espejo and C. Sagum with protein microarray work and the support from the Center for Environmental and Molecular Carcinogenesis at M.D. Anderson Cancer Center. This research is supported by US National Institutes of Health (NIH) grant CA132878 (G.M.), NIH grant CA137041 and James and Esther King grant 1KG02 (J.Q.C.), institutional NIH grant ES007784 and Cancer Prevention Research Institute of Texas grant RP110471 (M.T.B.) and NIH training grant 5T32ES007247 (A.I.B.).

\section{References}

1. Vousden KH, Prives C. Blinded by the light: the growing complexity of p53. Cell. 2009; 137:413431. [PubMed: 19410540]

2. Beckerman R, Prives C. Transcriptional regulation by p53. Cold Spring Harb Perspect Biol. 2010; 2:a000935. [PubMed: 20679336]

3. Huang J, et al. Repression of p53 activity by Smyd2-mediated methylation. Nature. 2006; 444:629632. [PubMed: 17108971]

4. Huang J, et al. p53 is regulated by the lysine demethylase LSD1. Nature. 2007; 449:105-108. [PubMed: 17805299]

5. Shi X, et al. Modulation of p53 function by SET8-mediated methylation at lysine 382 . Mol Cell. 2007; 27:636-646. [PubMed: 17707234] 
6. Kachirskaia I, et al. Role for 53BP1 Tudor domain recognition of p53 dimethylated at lysine 382 in DNA damage signaling. J Biol Chem. 2008; 283:34660-34666. [PubMed: 18840612]

7. Roy S, et al. Structural insight into p53 recognition by the 53BP1 tandem Tudor domain. J Mol Biol. 2010; 398:489-496. [PubMed: 20307547]

8. West LE, Gozani O. Regulation of p53 function by lysine methylation. Epigenomics. 2011; 3:361369. [PubMed: 21826189]

9. Joo WS, et al. Structure of the 53BP1 BRCT region bound to $\mathrm{p} 53$ and its comparison to the Brca1 BRCT structure. Genes Dev. 2002; 16:583-593. [PubMed: 11877378]

10. Derbyshire DJ, et al. Crystal structure of human 53BP1 BRCT domains bound to p53 tumour suppressor. EMBO J. 2002; 21:3863-3872. [PubMed: 12110597]

11. Cui G, Botuyan MV, Mer G. Preparation of recombinant peptides with site- and degree-specific lysine ${ }^{13}$ C-methylation. Biochemistry. 2009; 48:3798-3800. [PubMed: 19334741]

12. Kim J, et al. Tudor, MBT and chromo domains gauge the degree of lysine methylation. EMBO Rep. 2006; 7:397-403. [PubMed: 16415788]

13. Botuyan MV, et al. Structural basis for the methylation state-specific recognition of histone H4 K20 by 53BP1 and Crb2 in DNA repair. Cell. 2006; 127:1361-1373. [PubMed: 17190600]

14. Fischer U, et al. Glioma-expressed antigen 2 (GLEA2): a novel protein that can elicit immune responses in glioblastoma patients and some controls. Clin Exp Immunol. 2001; 126:206-213. [PubMed: 11703362]

15. Pallasch CP, et al. Autoantibodies against GLEA2 and PHF3 in glioblastoma: Tumor-associated autoantibodies correlated with prolonged survival. Int J Cancer. 2005; 117:456-459. [PubMed: 15906353]

16. Heisel SM, et al. Increased seroreactivity to glioma-expressed antigen 2 in brain tumor patients under radiation. PLoS ONE. 2008; 3:e2164. [PubMed: 18478111]

17. Park S, et al. Identification of an Akt interaction protein, PHF20/TZP, that transcriptionally regulates p53. J Biol Chem. 2012; 287:11151-11163. [PubMed: 22334668]

18. Dou Y, et al. Physical association and coordinate function of the H3 K4 methyltransferase MLL1 and the H4 K16 acetyltransferase MOF. Cell. 2005; 121:873-885. [PubMed: 15960975]

19. Taipale M, et al. hMOF histone acetyltransferase is required for histone H4 lysine 16 acetylation in mammalian cells. Mol Cell Biol. 2005; 25:6798-6810. [PubMed: 16024812]

20. Mendjan S, et al. Nuclear pore components are involved in the transcriptional regulation of dosage compensation in Drosophila. Mol Cell. 2006; 21:811-823. [PubMed: 16543150]

21. Li X, Wu L, Corsa CA, Kunkel S, Dou Y. Two mammalian MOF complexes regulate transcription activation by distinct mechanisms. Mol Cell. 2009; 36:290-301. [PubMed: 19854137]

22. Cai Y, et al. Subunit composition and substrate specificity of a MOF-containing histone acetyltransferase distinct from the male-specific lethal (MSL) complex. J Biol Chem. 2010; 285:4268-4272. [PubMed: 20018852]

23. Sykes SM, et al. Acetylation of the p53 DNA-binding domain regulates apoptosis induction. Mol Cell. 2006; 24:841-851. [PubMed: 17189187]

24. Yang WH, et al. Modification of p53 with O-linked N-acetylglucosamine regulates p53 activity and stability. Nat Cell Biol. 2006; 8:1074-1083. [PubMed: 16964247]

25. Badeaux AI, et al. Loss of the methyl lysine effector protein PHF20 impacts the expression of genes regulated by the lysine acetyltransferase MOF. J Biol Chem. 2012; 287:429-437. [PubMed: 22072714]

26. Huang Y, Fang J, Bedford MT, Zhang Y, Xu RM. Recognition of histone H3 lysine-4 methylation by the double tudor domain of JMJD2A. Science. 2006; 312:748-751. [PubMed: 16601153]

27. Lee J, Thompson JR, Botuyan MV, Mer G. Distinct binding modes specify the recognition of methylated histones H3K4 and H4K20 by JMJD2A-tudor. Nat Struct Mol Biol. 2008; 15:109-111. [PubMed: 18084306]

28. Brown MA, Sims RJ III, Gottlieb PD, Tucker PW. Identification and characterization of Smyd2: a split SET/MYND domain-containing histone $\mathrm{H} 3$ lysine 36-specific methyltransferase that interacts with the Sin3 histone deacetylase complex. Mol Cancer. 2006; 5:26. [PubMed: 16805913] 
29. Xiao B, et al. Specificity and mechanism of the histone methyltransferase Pr-Set7. Genes Dev. 2005; 19:1444-1454. [PubMed: 15933069]

30. Couture JF, Collazo E, Brunzelle JS, Trievel RC. Structural and functional analysis of SET8, a histone H4 Lys-20 methyltransferase. Genes Dev. 2005; 19:1455-1465. [PubMed: 15933070]

31. Selenko P, et al. In situ observation of protein phosphorylation by high-resolution NMR spectroscopy. Nat Struct Mol Biol. 2008; 15:321-329. [PubMed: 18297086]

32. Ito Y, Selenko P. Cellular structural biology. Curr Opin Struct Biol. 2010; 20:640-648. [PubMed: 20801639]

33. Liokatis S, Dose A, Schwarzer D, Selenko P. Simultaneous detection of protein phosphorylation and acetylation by high-resolution NMR spectroscopy. J Am Chem Soc. 2010; 132:14704-14705. [PubMed: 20886851]

34. Xu C, Cui G, Botuyan MV, Mer G. Structural basis for the recognition of methylated histone H3K36 by the Eaf3 subunit of histone deacetylase complex Rpd3S. Structure. 2008; 16:17401750. [PubMed: 18818090]

35. Brooks CL, Gu W. p53 ubiquitination: Mdm2 and beyond. Mol Cell. 2006; 21:307-315. [PubMed: 16455486]

36. Meek DW, Anderson CW. Posttranslational modification of p53: cooperative integrators of function. Cold Spring Harb Perspect Biol. 2009; 1:a000950. [PubMed: 20457558]

37. Poyurovsky MV, et al. The $\mathrm{C}$ terminus of $\mathrm{p} 53$ binds the N-terminal domain of MDM2. Nat Struct Mol Biol. 2010; 17:982-989. [PubMed: 20639885]

38. Adams-Cioaba MA, et al. Structural studies of the tandem Tudor domains of fragile X mental retardation related proteins FXR1 and FXR2. PLoS ONE. 2010; 5:e13559. [PubMed: 21072162]

39. Tripsianes K, et al. Structural basis for dimethylarginine recognition by the Tudor domains of human SMN and SPF30 proteins. Nat Struct Mol Biol. 2011; 18:1414-1420. [PubMed: 22101937]

40. Li B, et al. Combined action of PHD and chromo domains directs the Rpd3S HDAC to transcribed chromatin. Science. 2007; 316:1050-1054. [PubMed: 17510366]

41. Ruthenburg AJ, Li H, Patel DJ, Allis CD. Multivalent engagement of chromatin modifications by linked binding modules. Nat Rev Mol Cell Biol. 2007; 8:983-994. [PubMed: 18037899]

42. Wang Z, Patel DJ. Combinatorial readout of dual histone modifications by paired chromatinassociated modules. J Biol Chem. 2011; 286:18363-18368. [PubMed: 21454653]

43. Horton JR, et al. Enzymatic and structural insights for substrate specificity of a family of jumonji histone lysine demethylases. Nat Struct Mol Biol. 2010; 17:38-43. [PubMed: 20023638]

44. Benezra R. An intermolecular disulfide bond stabilizes E2A homodimers and is required for DNA binding at physiological temperatures. Cell. 1994; 79:1057-1067. [PubMed: 8001133]

45. Mayo LD, Donner DB. A phosphatidylinositol 3-kinase/Akt pathway promotes translocation of Mdm2 from the cytoplasm to the nucleus. Proc Natl Acad Sci USA. 2001; 98:11598-11603. [PubMed: 11504915]

46. Botuyan MV, et al. Structural basis of BACH1 phosphopeptide recognition by BRCA1 tandem BRCT domains. Structure. 2004; 12:1137-1146. [PubMed: 15242590]

47. Simon MD, et al. The site-specific installation of methyl-lysine analogs into recombinant histones. Cell. 2007; 128:1003-1012. [PubMed: 17350582]

48. Otwinowski Z, Minor W. Processing of X-ray diffraction data collected in oscillation mode. Methods Enzymol. 1997; 276:307-326.

49. Kelley LA, Sternberg MJ. Protein structure prediction on the Web: a case study using the Phyre server. Nat Protoc. 2009; 4:363-371. [PubMed: 19247286]

50. Emsley P, Cowtan K. Coot: model-building tools for molecular graphics. Acta Crystallogr D Biol Crystallogr. 2004; 60:2126-2132. [PubMed: 15572765]

51. Adams PD, et al. PHENIX: a comprehensive Python-based system for macromolecular structure solution. Acta Crystallogr D Biol Crystallogr. 2010; 66:213-221. [PubMed: 20124702]

52. Delaglio F, et al. NMRPipe: a multidimensional spectral processing system based on UNIX pipes. J Biomol NMR. 1995; 6:277-293. [PubMed: 8520220]

53. Johnson BA, Blevins RA. NMRView: a computer program for visualization and analysis of NMR data. J Biomol NMR. 1994; 4:603-614. [PubMed: 22911360] 
54. Duggan BM, Legge GB, Dyson HJ, Wright PE. SANE (Structure Assisted NOE Evaluation): an automated model-based approach for NOE assignment. J Biomol NMR. 2001; 19:321-329. [PubMed: 11370778]

55. Cornilescu G, Delaglio F, Bax A. Protein backbone angle restraints from searching a database for chemical shift and sequence homology. J Biomol NMR. 1999; 13:289-302. [PubMed: 10212987]

56. Wishart DS, Sykes BD. The ${ }^{13} \mathrm{C}$ chemical-shift index: a simple method for the identification of protein secondary structure using ${ }^{13} \mathrm{C}$ chemical-shift data. J Biomol NMR. 1994; 4:171-180. [PubMed: 8019132]

57. Güntert P. Automated NMR structure calculation with CYANA. Methods Mol Biol. 2004; 278:353-378. [PubMed: 15318003]

58. Case DA, et al. The Amber biomolecular simulation programs. J Comput Chem. 2005; 26:16681688. [PubMed: 16200636]

59. Laskowski RA, Rullmannn JA, MacArthur MW, Kaptein R, Thornton JM. AQUA and PROCHECK-NMR: programs for checking the quality of protein structures solved by NMR. J Biomol NMR. 1996; 8:477-486. [PubMed: 9008363]

60. Koradi R, Billeter M, Wüthrich K. MOLMOL: a program for display and analysis of macromolecular structures. J Mol Graph. 1996; 14:51-55. [PubMed: 8744573] 
a

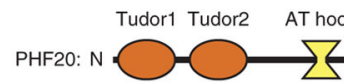

$\mathrm{C}_{2} \mathrm{H}_{2}$ zinc finger

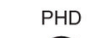
PHD

C

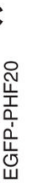

b
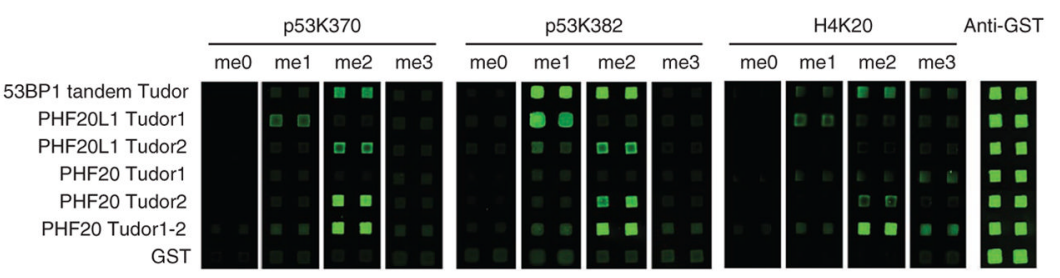
C 1,012

d
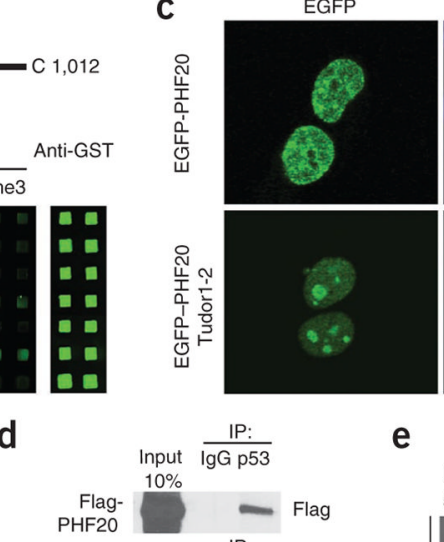

EGFP
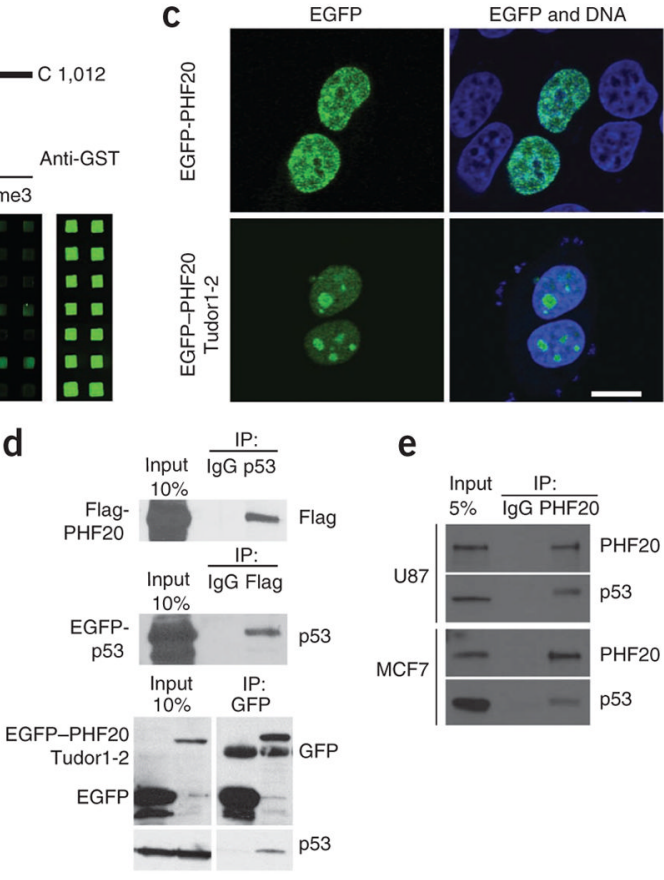

Figure 1.

Interaction of PHF20 with p53 in vitro and in cells. (a) Domain structure of human PHF20. (b) Protein array analysis of the Tudor domains of PHF20, homolog PHF20L1 and 53BP1 probed with fluorophore-tagged methylated p53 and histone H4 peptides. Proteins with Nterminal glutathione $S$-transferase (GST) tag were spotted on nitrocellulose-coated glass slides and probed with Cy3 dye-labeled 18 -amino acid p53 or $\mathrm{H} 4$ peptides centered on the denoted methylated lysine, synthesized to contain a non- (me0), mono- (me1), di- (me2) or tri-methylated (me3) lysine. An analysis with an anti-GST antibody confirmed equal spotting of all domains. (c) Fluorescence micrographs showing cellular localization of fulllength EGFP-PHF20 and EGFP-PHF20 Tudor1-2. Scale bar, $10 \mu \mathrm{m}$. (d) Immunoprecipitation of EGFP-p53 and Flag-PHF20 using anti-p53 and anti-Flag antibodies, respectively, from lysates of HEK 293 cells transfected with plasmids encoding both FlagPHF20 and EGFP-p53; co-immunoprecipitated protein (Flag-PHF20 or EGFP-p53) was detected by western blot (WB) using the respective antibody. In HEK 293 cells transfected with a plasmid encoding EGFP-PHF20 Tudor1-2 or EGFP, EGFP-PHF20 Tudor1-2 was immunoprecipitated using an anti-GFP antibody, and endogenous p53 was detected by WB using an anti-p53 antibody. (e) Immunoprecipitation of endogenous PHF20 from U87 and MCF7 cells lysates using an anti-PHF20 antibody. Co-IP of p53 was detected by WB using an anti-p53 antibody. 
a

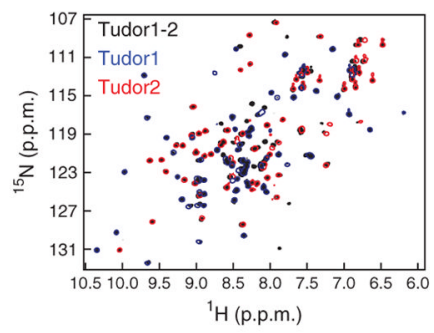

b

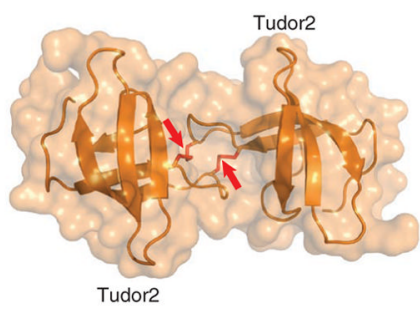

C

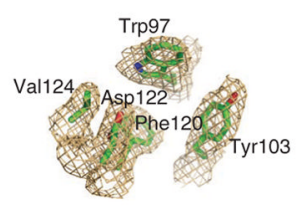

d

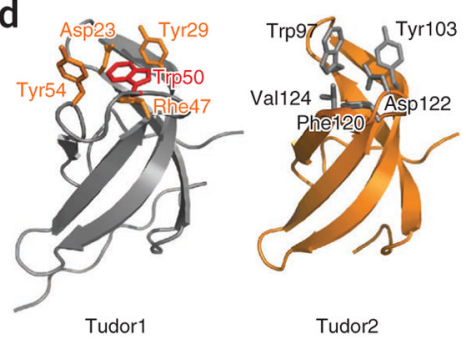

Figure 2.

Structures of PHF20 Tudor1 and Tudor2. (a) Overlaid ${ }^{1} \mathrm{H}_{-}{ }^{15} \mathrm{~N}$ HSQC spectra of PHF20 Tudor1 (amino acids 1-83), Tudor2 (amino acids 84-147) and Tudor1-2 (amino acids 1147) with C96S and C100S mutations. (b) Structure of PHF20 Tudor2 dimer in surface and ribbon representation, with the disulfide bonds marked by arrows. (c) Side chains of the methyllysine binding cage residues of PHF20 Tudor2 with the corresponding $2 F_{\mathrm{O}}-F_{\mathrm{C}}$ electron density map contoured at $1 \sigma$ level. (d) Structures of PHF20 Tudor1 and Tudor2. Methylated lysine-binding residues of PHF20 Tudor2 and corresponding residues of PHF20 Tudor1 are shown. The side chain of PHF20 Tudor1 Trp50 blocking the cavity is in red. 
a

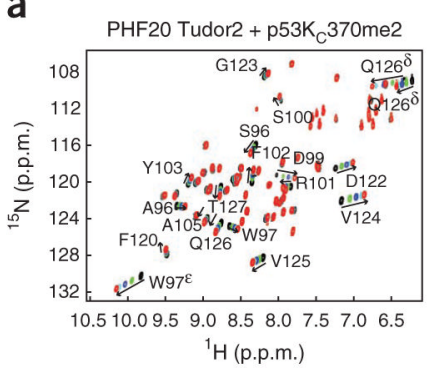

b

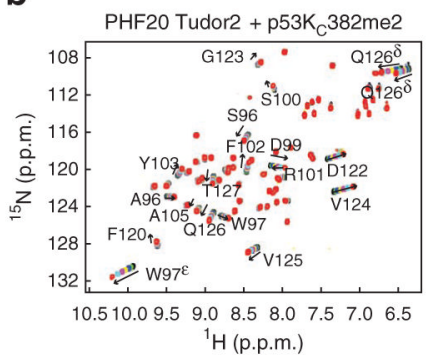

C

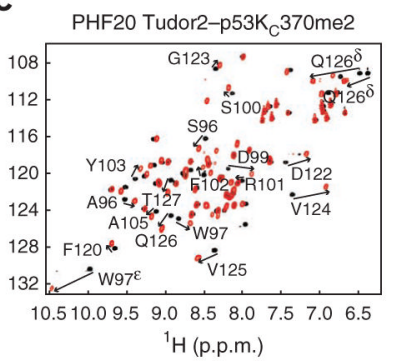

d

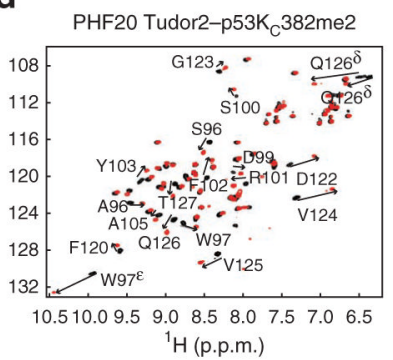

e

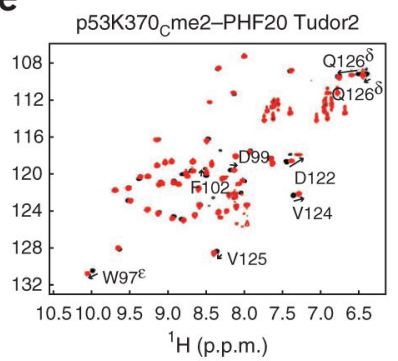

f

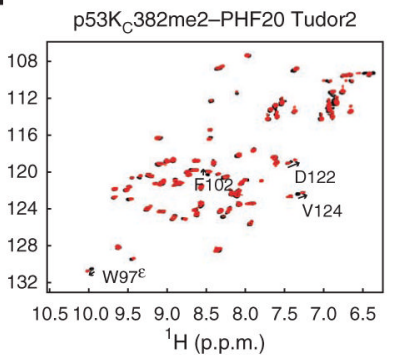

g

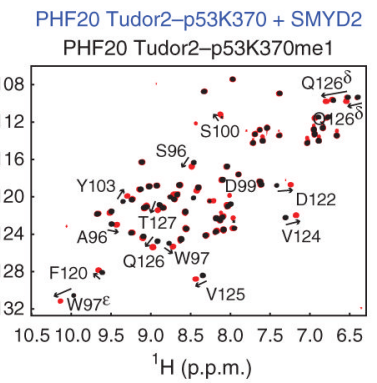

h

PHF20 Tudor2-p53K382 + SET8

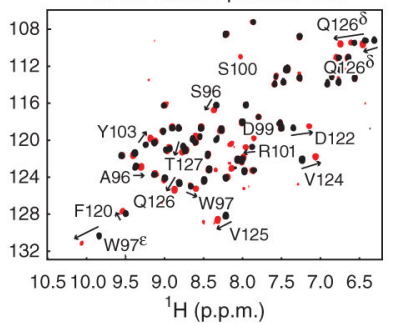

i
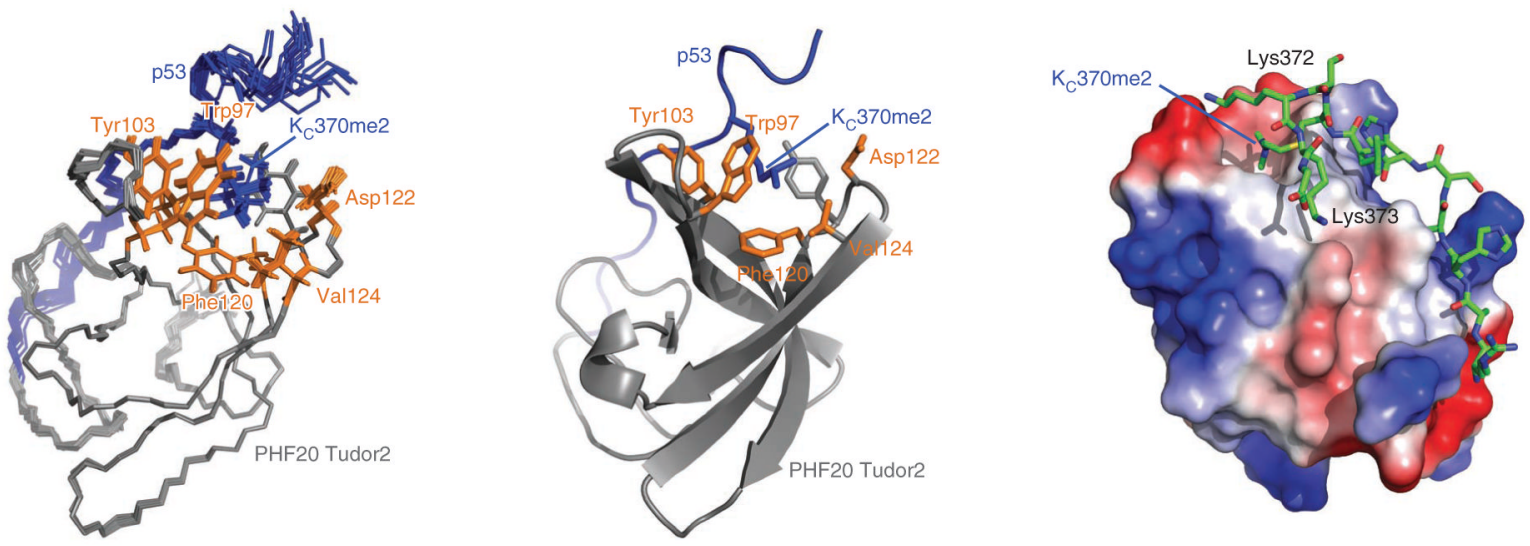

Figure 3.

Chemical dimethylation and enzymatic monomethylation of p53 at Lys370 or Lys382, and interaction of methylated p53 with PHF20 Tudor2. (a,b) ${ }^{1} \mathrm{H}_{-}{ }^{15} \mathrm{~N}$ HSQC titration spectra of mPHF20 Tudor2 with a p53 $\mathrm{K}_{\mathrm{C}} 370 \mathrm{me} 2$ peptide (a) and with a $553 \mathrm{~K}_{\mathrm{C}} 382 \mathrm{me} 2$ peptide (b). (c-f) Overlaid ${ }^{1} \mathrm{H}_{-}{ }^{15} \mathrm{~N}$ HSQC spectra of PHF20 Tudor2-p53C370 and PHF20 Tudor2p53K $370 \mathrm{me} 2(\mathbf{c})$, PHF20 Tudor2-p53C382 and PHF20 Tudor2-p53K $382 \mathrm{me} 2(\mathbf{d})$, p53C370-PHF20 Tudor2 and p53K 3 370me2-PHF20 Tudor2 (e), and p53C382-PHF20 Tudor2 and p53K $\mathrm{K}_{\mathrm{C}} 382 \mathrm{me} 2-\mathrm{PHF} 20$ Tudor2 (f). (g,h) Overlaid ${ }^{1} \mathrm{H}_{-}{ }^{15} \mathrm{~N}$ HSQC spectra of PHF20 Tudor2-p53K370 and PHF20 Tudor2-p53K370me1 monomethylated by SMYD2 (g) and of PHF20 Tudor2-p53K382 and PHF20 Tudor2-p53K382me1 monomethylated by SET8 (h). (i) Superposition of the 20 lowest energy structures of PHF20 Tudor2p53 $\mathrm{K}_{\mathrm{C}} 370 \mathrm{me} 2$ with $\mathrm{N}, \mathrm{C}^{\mathrm{a}}$ and $\mathrm{C}^{\prime}$ backbone atoms in line representation (left) and ribbon representation of the lowest energy structure (middle). Residues 83-147 of PHF20 and 363374 of p53 are colored gray and blue, respectively; side chains of dimethyllysine binding cage residues are shown in orange. Surface electrostatic potential of PHF20 Tudor2 in the PHF20 Tudor2-p53 $\mathrm{K}_{\mathrm{C}} 370 \mathrm{me} 2$ linked complex and $\mathrm{p} 53$ segment in stick representation (right). 
a

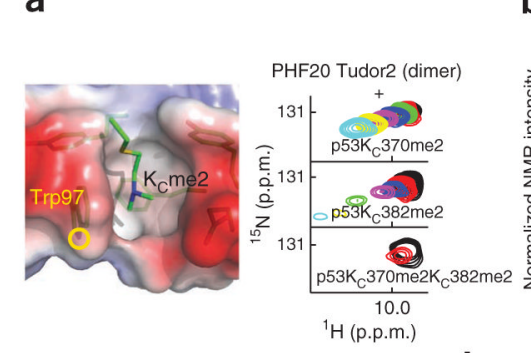

b

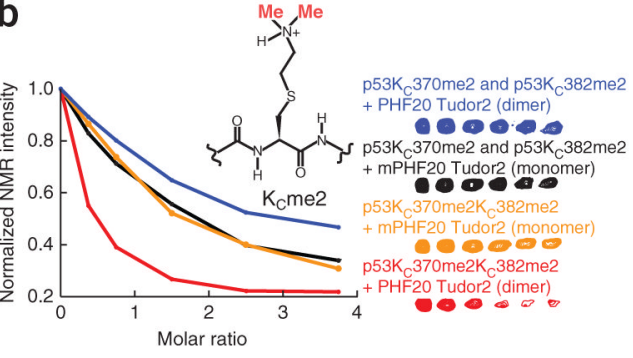

d

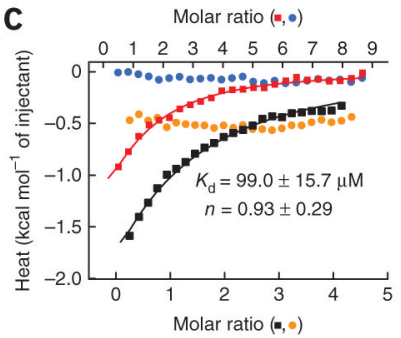

d 553

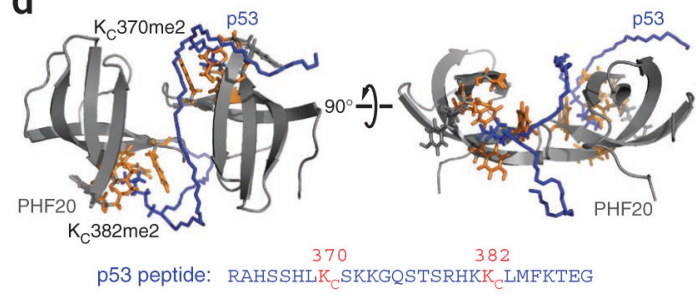

Figure 4.

Evidence for dual recognition of p53K370me2K382me2 by PHF20 Tudor2 dimer. (a) Location of Trp97 and its indole NH group in the dimethyllysine binding site of PHF20 Tudor2, taken from the NMR structure of PHF20 Tudor2-p53 $\mathrm{K}_{\mathrm{C}} 370 \mathrm{me} 2$ linked complex (left). Changes in the signal of Trp97 indole NH spin pair in the ${ }^{1} \mathrm{H}_{-}{ }^{15} \mathrm{~N}$ HSQC spectrum of

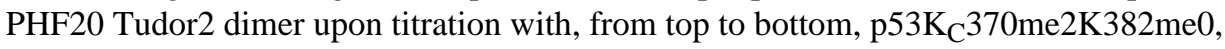
$\mathrm{p} 53 \mathrm{~K} 370 \mathrm{me} 0 \mathrm{~K}_{\mathrm{C}} 382 \mathrm{me} 2$ and $\mathrm{p} 53 \mathrm{~K}_{\mathrm{C}} 370 \mathrm{me} 2 \mathrm{~K}_{\mathrm{C}} 382 \mathrm{me} 2$ peptides (right). (b) Changes in ${ }^{1} \mathrm{H}_{-}{ }^{13} \mathrm{C}$ HSQC signal intensity of $\mathrm{K}_{\mathrm{C}} \mathrm{me} 2$ in p53 upon titration of $\mathrm{p} 53 \mathrm{~K}_{\mathrm{C}} 370 \mathrm{me} 2 \mathrm{~K}_{\mathrm{C}} 382 \mathrm{me} 2$ and an equimolar mixture of $\mathrm{p} 53 \mathrm{~K}_{\mathrm{C}} 370 \mathrm{me} 2 \mathrm{~K} 382 \mathrm{me} 0$ and p53K370me0 $\mathrm{K}_{\mathrm{C}} 382 \mathrm{me} 2$ with dimeric PHF20 Tudor2, represented by red and blue lines, respectively; similar titrations as above but with monomeric mPHF20 Tudor2 are shown in orange and black lines (left). ${ }^{1} \mathrm{H}_{-}{ }^{13} \mathrm{C}$ HSQC correlation signals used to measure the $\mathrm{K}_{\mathrm{C}}$ me2 intensities in $\mathrm{p} 53$ (right). (c) ITC analysis of the $\mathrm{p} 53 \mathrm{~K}_{\mathrm{C}} 370 \mathrm{me} 2 \mathrm{~K}_{\mathrm{C}} 382 \mathrm{me} 2$ peptide (amino acids 363-389) with PHF20 Tudor2 dimer and mPHF20 Tudor2. The p53 peptide (4 mM) was injected in the calorimeter cell containing initial concentrations of $50 \mu \mathrm{M}$ and $100 \mu \mathrm{M}$ of PHF20 Tudor 2 dimer (red and black curves, respectively), and $100 \mu \mathrm{M}$ and $200 \mu \mathrm{M}$ of mPHF20 Tudor2 (blue and orange curves, respectively). Apparent $K_{\mathrm{d}}$, stoichiometry $(n)$ and s.d. are indicated. The top $\mathrm{x}$ axis is for the red and blue curves. The bottom $\mathrm{x}$ axis is for the black and orange curves. (d) Model of PHF20 Tudor2 in complex with $\mathrm{p} 53 \mathrm{~K}_{\mathrm{C}} 370 \mathrm{me} 2 \mathrm{~K}_{\mathrm{C}} 382 \mathrm{me} 2$ obtained from docking calculations using the crystal structure of PHF20 Tudor2. 
a

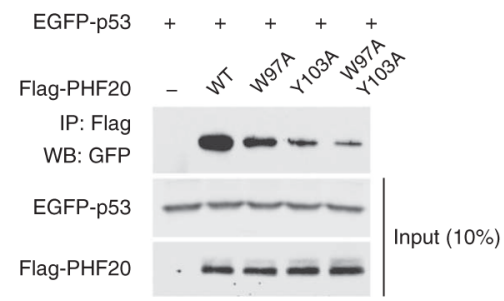

b

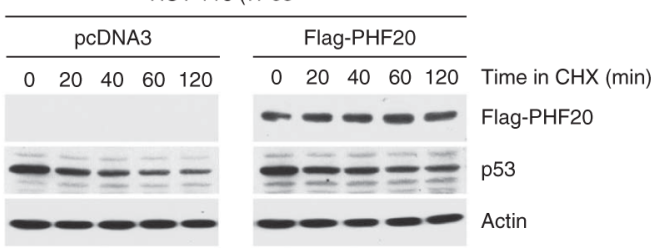

C

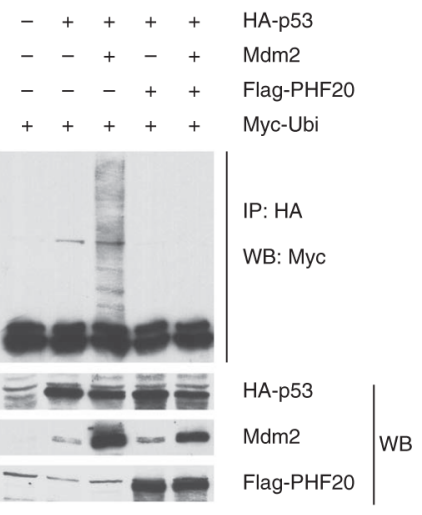

Figure 5.

PHF20 interacts with the methylated region of p53 and stabilizes p53 in cells. (a) Western blots (WB) with antibodies to the indicated tags after co-IP with an anti-Flag antibody of full-length EGFP-p53 with wild-type (WT) and indicated mutants of full-length FlagPHF20. The W97A and Y103A mutations are in PHF20 Tudor2 domain. HEK 293 cells were transfected with plasmids encoding Flag-PHF20 and EGFP-p53. (b) HCT 116

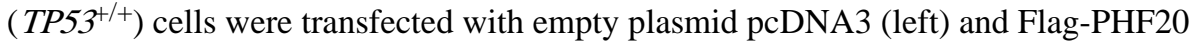
plasmid (right) and after $36 \mathrm{~h}$ were treated with $100 \mu \mathrm{M}$ cycloheximide (CHX) for the durations indicated. Proteins in the cell lysates were identified by WB with anti-Flag, antip53 and anti-actin antibodies. (c) HCT $116\left(\right.$ TP53 $\left.^{--}\right)$cells were transfected with HA-p53, Mdm2, Flag-PHF20 and Myc-ubiquitin as indicated and after $48 \mathrm{~h}$ were immunoprecipitated with anti-HA antibody and immunoblotted with anti-Myc antibody (top). Indicated proteins were also immunoblotted (bottom). 
a

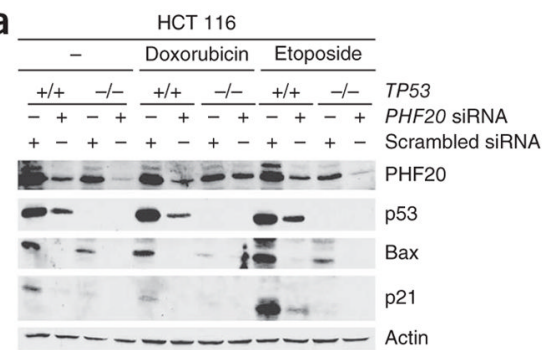

b

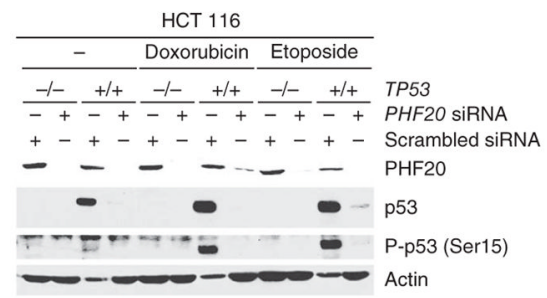

C

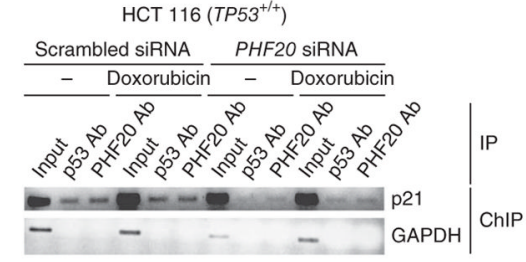

Figure 6.

Knockdown of PHF20 reduces p53 upregulation induced by DNA damage. (a) Immunoblots of indicated proteins in lysates from HCT $116\left(\right.$ TP53 $\left.^{+/+}\right)$and HCT $116\left(\right.$ TP53 $\left.^{-/-}\right)$cells transfected with $P H F 20$-specific and scrambled siRNA and $68 \mathrm{~h}$ later treated with $10 \mu \mathrm{M}$ doxorubicin or $100 \mu \mathrm{M}$ etoposide for $4 \mathrm{~h}$. (b) Immunoblots as in a, but with an antibody specific for p53 phosphorylated at Ser15 (P-p53). (c) ChIP assay, using primers derived from the p21 promoter sequence, in HCT $116\left(\mathrm{TP}^{\mathrm{H}} \mathrm{3}^{+/+}\right)$cells transfected with $\mathrm{PHF} 20$ specific and scrambled siRNA and then treated with doxorubicin. 
a

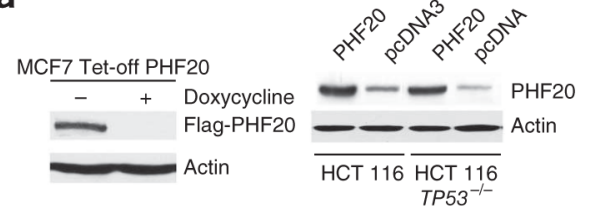

b

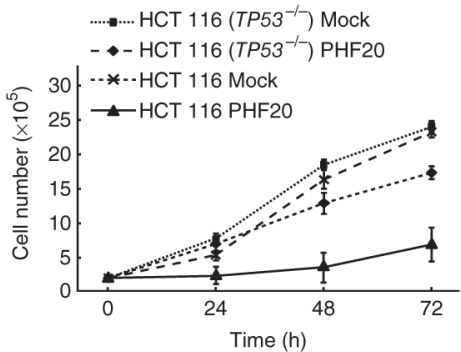

C
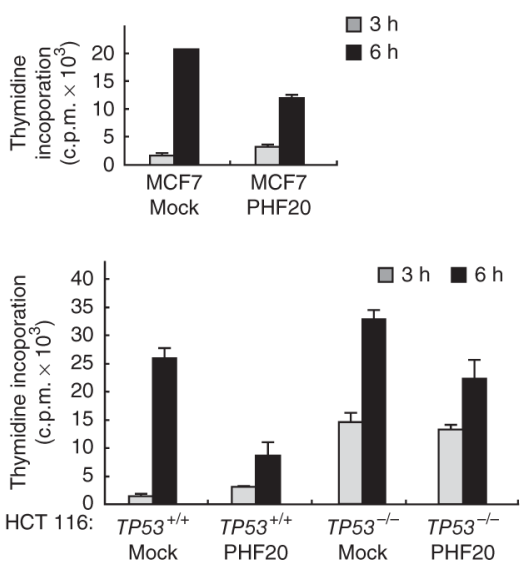

d
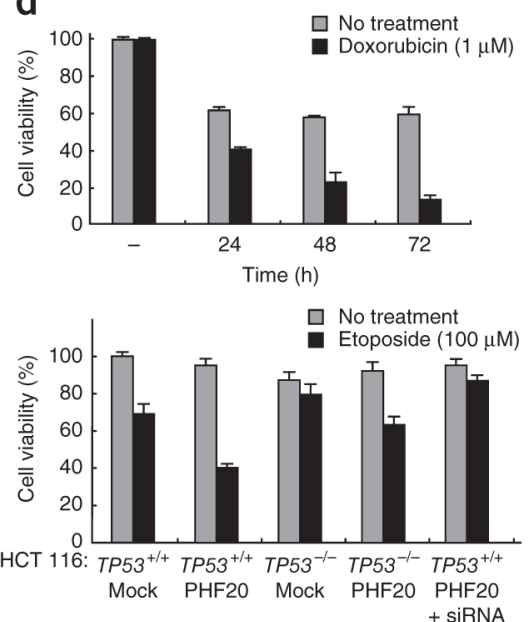

पS G G2-M $\square \mathrm{G} 1$

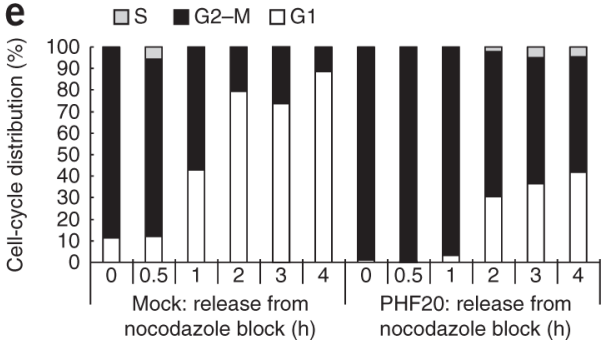

Figure 7.

Ectopic expression of PHF20 leads to phenotypic changes consistent with p53 activation. (a) Western blot (WB) analysis showing controlled expression of Flag-PHF20 in MCF7 Tet-off cells (MCF7 Tet-off PHF20). HCT $116\left(\right.$ TP53 $\left.^{+/+}\right)$and HCT $116($ TP53-/- $)$ cells were transfected with a plasmid encoding PHF20 or empty plasmid pcDNA3, and proteins in the cell lysates were identified by WB using anti-PHF20 and anti-actin antibodies (right). (b) HCT $116\left(\right.$ TP53 $\left.^{+/+}\right)$and HCT $116($ TP53-/- $)$ cells transfected with a PHF20-encoding plasmid or pcDNA3 (Mock) were grown and counted at the indicated times. Error bars, s.d. from triplicate experiments. (c) Incorporation of ${ }^{3} \mathrm{H}$-enriched thymidine in MCF7, HCT 116 $\left(\right.$ TP53 $\left.^{+++}\right)$and HCT $116\left(\right.$ TP53 $\left.^{--}\right)$cells transfected with a PHF20-encoding plasmid or pcDNA3 (Mock) was monitored at the indicated times. Error bars, s.d. from triplicate experiments. (d) PHF20-encoding-plasmid-transfected or pcDNA3-transfected (Mock) MCF7 Tet-off, HCT $116\left(\right.$ TP53 $\left.^{+/+}\right)$or HCT $116\left(\right.$ TP53 $\left.3^{--}\right)$cells were treated with $1 \mu \mathrm{M}$ doxorubicin for the indicated times or with $100 \mu \mathrm{M}$ etoposide for $4 \mathrm{~h}$. Error bars, s.d. from triplicate experiments. (e) Flow cytometry analysis of fixed MCF7 Tet-off PHF20 cells and control MCF7 Tet-off cells (Mock) that had been cultured in the absence of doxycycline for $12 \mathrm{~h}$ and subsequently treated with nocodazole for $12 \mathrm{~h}$, washed and grown in fresh nocodazole-free medium for 1-4 h. 
Table 1

Data collection and refinement statistics

\begin{tabular}{|c|c|c|}
\hline & PHF20 Tudor $1^{a}$ & PHF20 Tudor $2^{a}$ \\
\hline \multicolumn{3}{|l|}{ Data collection } \\
\hline Space group & $P 2_{1}$ & $\mathrm{PH}_{3}$ \\
\hline \multicolumn{3}{|l|}{ Cell dimensions } \\
\hline$a, b, c(\AA)$ & $37.75,60.76,37.75$ & $48.55,48.55,96.15$ \\
\hline$a, \beta, \gamma\left(^{\circ}\right)$ & $90.00,112.82,90.00$ & $90.00,90.00,90.00$ \\
\hline Resolution ( $(̊)$ & $30.38-1.93(1.96-1.93)^{b}$ & $23.54-2.00(2.07-2.00)$ \\
\hline$R_{\text {merge }}$ & $0.050(0.370)$ & $0.058(0.315)$ \\
\hline$I / \sigma I$ & $16.3(7.2)$ & $31.8(3.6)$ \\
\hline Completeness (\%) & $98.1(95.9)$ & $99.3(95.6)$ \\
\hline Redundancy & $7.1(7.0)$ & $8.1(6.8)$ \\
\hline \multicolumn{3}{|l|}{ Refinement } \\
\hline Resolution ( $($ ) & $30.38-1.93(2.12-1.93)$ & $23.54-2.00(2.15-2.00)$ \\
\hline No. reflections & $11,693(2,729)$ & $14,859(2,900)$ \\
\hline$R_{\text {work }} / R_{\text {free }}$ & $0.229 / 0.236$ & $0.235 / 0.262$ \\
\hline \multicolumn{3}{|l|}{ No. atoms } \\
\hline Protein & 2,327 & 888 \\
\hline Water & 215 & 157 \\
\hline \multicolumn{3}{|l|}{$B$-factors } \\
\hline Protein & 33.4 & 53.9 \\
\hline Water & 37.2 & 60.1 \\
\hline \multicolumn{3}{|l|}{ R.m.s. deviations } \\
\hline Bond lengths $(\AA)$ & 0.005 & 0.003 \\
\hline \multicolumn{3}{|l|}{ Ramachandran plot } \\
\hline Favored region (\%) & 96.4 & 96.2 \\
\hline Allowed region $(\%)$ & 3.6 & 1.9 \\
\hline
\end{tabular}


Table 2

NMR and refinement statistics

\begin{tabular}{|c|c|}
\hline & PHF20 Tudor2-p53K $\mathrm{C}_{\mathrm{C}} 370 \mathrm{me} 2$ \\
\hline \multicolumn{2}{|l|}{ NMR distance and dihedral constraints } \\
\hline \multicolumn{2}{|l|}{ Distance constraints } \\
\hline Total NOE & 3,022 \\
\hline Intra-residue & 479 \\
\hline Sequential $(|i-\jmath|=1)$ & 476 \\
\hline Medium-range $(|i-\lambda|<5)$ & 260 \\
\hline Long-range $(|i-\lambda| \geq 5)$ & 666 \\
\hline Ambiguous & 1,141 \\
\hline Hydrogen bonds & 27 \\
\hline Total dihedral angle restraints & 105 \\
\hline$\varphi$ & 32 \\
\hline$\psi$ & 33 \\
\hline$\chi^{1}$ & 40 \\
\hline \multicolumn{2}{|l|}{ Structure statistics } \\
\hline \multicolumn{2}{|l|}{ Violations (mean and s.d.) } \\
\hline Distance constraints $(\AA)$ & $0.10 \pm 0.02$ \\
\hline Dihedral angle constraints $\left(^{\circ}\right)$ & $2.66 \pm 0.94$ \\
\hline Max. dihedral angle violation $\left({ }^{\circ}\right)$ & $3.98 \pm 0.37$ \\
\hline Max. distance constraint violation $(\AA)$ & $0.21 \pm 0.01$ \\
\hline \multicolumn{2}{|l|}{ Deviations from idealized geometry } \\
\hline Bond lengths $(\AA)$ & $0.0085 \pm 0.0001$ \\
\hline Bond angles $\left({ }^{\circ}\right)$ & $2.15 \pm 0.02$ \\
\hline Impropers $\left(^{\circ}\right)$ & $0.22 \pm 0.02$ \\
\hline \multicolumn{2}{|l|}{ Average pairwise r.m.s. deviation ${ }^{a}(\AA)$} \\
\hline Heavy & $0.72 \pm 0.11$ \\
\hline \multicolumn{2}{|l|}{ Ramachandran plot } \\
\hline Favored region $(\%)$ & 88.9 \\
\hline Allowed region $(\%)$ & 9.7 \\
\hline
\end{tabular}

${ }^{a}$ Pairwise r.m.s. deviation was calculated for residues 91-138 from an ensemble of 20 structures. 